\title{
Objetos litúrgicos de peltre hallados en contextos funerarios de época medieval: El cáliz y patena de la Pobla de Ifach (Calp, Alicante)
}

\section{Liturgical pewter objects found in funerary contexts of medieval times: The chalice and pathena of the medieval village of Ifach (Calp, Alicante)}

\author{
José Luis Menéndez Fueyo* \\ Joaquín Pina Mira** \\ Stefania Malagutti ${ }^{\star \star *}$ \\ Recibido: 30/05/2019 - Enviado a Evaluación: 04/06/2019 - Aprobado: 06/07/2019
}

\begin{abstract}
RESUMEN
El objetivo del artículo es presentar los datos y contexto arqueológico de un grial y una patena de peltre encontradas en una tumba de la necrópolis medieval de la Pobla de Ifach (Calp, Alicante). Son piezas litúrgicas, cuya difusión es muy amplia por el territorio catalán y que aparecen siempre asociadas a los ajuares funerarios de clérigos o miembros del estamento clerical vinculados con la iglesia.
\end{abstract}

Palabras clave: Ifach, Calp, MARQ, grial, medieval

La investigación arqueológica que el Museo Arqueológico de Alicante (MARQ) ${ }^{1}$ junto al Ayuntamiento de Calp y el Parque Natural del Penyal d'Ifac, dependiente de la Consellería de Agricultura, Medio Ambiente, Cambio Climático y Desarrollo Rural de la Generalitat Valenciana está desarrollando en el yacimiento medieval de la Pobla de Ifach (Calp, Alicante) (Figura 1), ha ofrecido en estos últimos 15 años un enorme registro material que afecta a la cerámica, el vidrio, la numismática, los siempre importantes registros medioambientales y los metales. Precisamente, uno de estos registros metálicos ha levantado un gran interés en el equipo de investigación del yacimiento por el tipo de pieza y por

\begin{abstract}
The aim is present the data and archaeological context of a chalice and pathena found in a to mb of the necropolis of medieval village of Ifach (Calp, Alicante). They are liturgical pieces, whose diffusion is very wide in the catalan territory and which are associated with the funeral trousseaux of a clerical membre linked to the medieval church of Ifach.
\end{abstract}

Key words: Ifach, Calp. MARQ, grail, medieval

las circunstancias de su hallazgo. Nos estamos refiriendo al descubrimiento en la IX campaña de excavaciones realizada en el año 2013 de los restos de un cáliz y una patena dentro de una las tumbas ubicadas en el cimiterium o área funeraria de época medieval de la pobla de Ifach.

La Pobla de Ifach (Figura 2) se está convirtiendo en un referente arqueológico para el estudio del modelo de asentamiento medieval post-conquista cristiana vinculado directamente a la génesis y creación del Reino de Valencia, el cual no nace exclusivamente de conquistas militares de mayor o menor rango, ni de los complejos pactos que hubo que tejer entre la mayoritaria

\footnotetext{
* Director del projecto de investigación a la Pobla medieval de Ifach. Museu Arqueológico de Alicante (MARQ). Plaza Dr. Gómez Ulla, s/n.03013 Alicante.jmenende@diputacionalicante.es. ** Arqueologo. Avenida de Alcoy, 9, $7^{\circ}$ Izquierda, 03004 Alicante, ascanio78@ hotmail.com. ${ }^{* *}$ Paleoantropóloga. Calle Santa Julia, 6, $2^{\circ}$ derecha 28053 Madrid stefaniamalagutti@yahoo.it

1. Esta investigación ha sido financiada con los fondos adscritos al proyecto de investigación de la Pobla de Ifach que se halla dentro del Plan Anual de Excavaciones Arqueológicas del Museo Arqueologico de Alicante, cuya partida se inserta en los Presupuestos Generales de la Diputación Provincial de Alicante.
} 


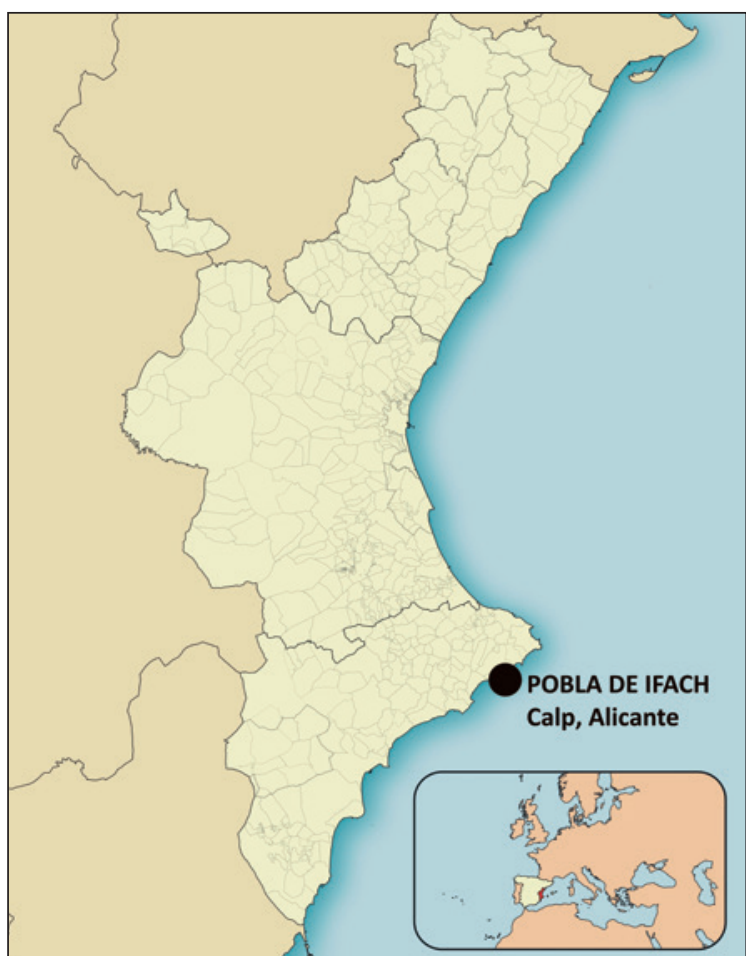

Figura 1. Situación geográfica del yacimiento medieval de la Pobla de Ifach (Calp, Alicante).

población musulmana, sino que se fundamenta en una conquista pacífica de pobladores, en gente trasladada desde otros puntos del reino para colonizar y desarrollar el nuevo modelo feudal, rompiendo así el engranaje socioeconómico de un mundo andalusí mayoritario, pero en decadencia. Esta sencilla explicación tiene su plasmación arqueológica en diversos estudios centrados en la búsqueda del reconocimiento de estas huellas de la primera presencia feudal en el complejo mapa de la arqueología medieval valenciana.

\section{EL YACIMIENTO DEL HALLAZGO. LA POBLA MEDIEVAL DE IFACH}

Las bases de nuestra investigación sobre la pobla de Ifach se han centrado en una importante historiografía ${ }^{2}$ y en la intensa actividad

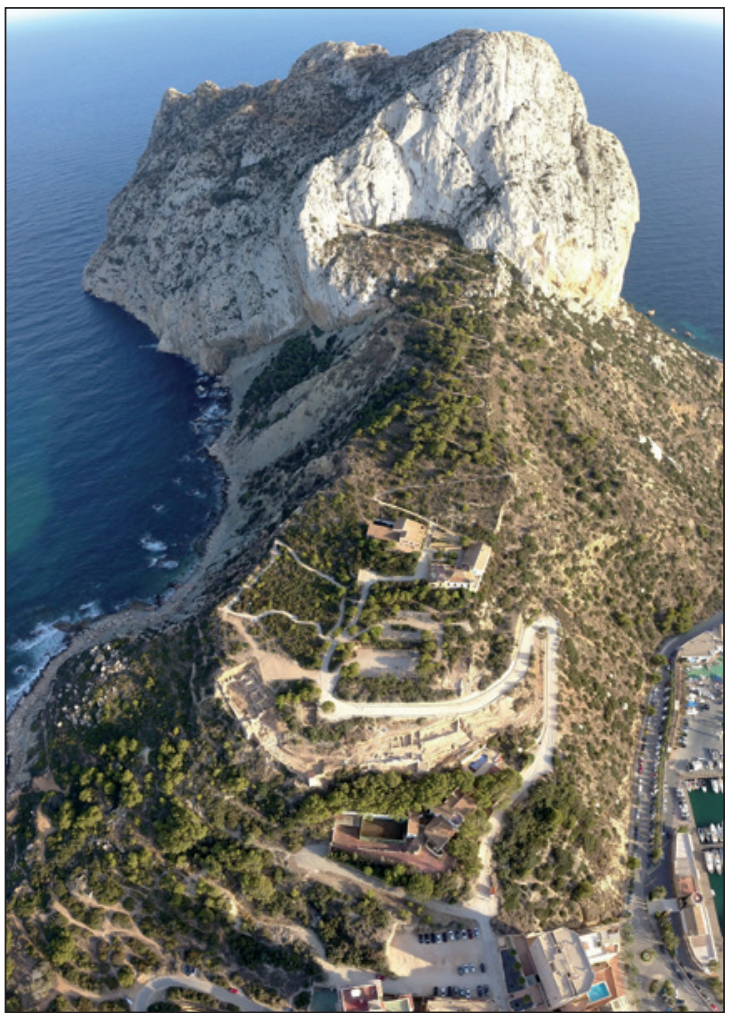

Figura 2. Vista panorámica del yacimiento medieval de la Pobla de Ifach en la ladera del Penyal d'Ifac en Calp. Archivo Gráfico MARQ.

\footnotetext{
2. Desde bien antiguo, la roca calpina de Ifach ha despertado la admiración y el interés de ilustrados, botánicos, geógrafos, historiadores, arqueólogos, cronistas locales e incluso de literatos y artistas quienes han plasmado en sus escritos y grabados las diferentes visiones que esta mole pétrea en la que se ubica la pobla medieval de Ifach les fue produciendo. Una visión más profunda se ha plasmado en un reciente trabajo inserto en la primera monografía sobre la pobla medieval (Menéndez Fueyo, 2018b: 23-43) en el podemos destacar un elenco de obras situadas en los siglos XVI al XIX como la Primera parte de la historia de Valencia del año 1538 de Pedro Antonio Beuter (1490-1554); la Década primera de la historia de la insigne y coronada ciudad y reyno de Valencia de Gaspar Juan Escolano en el año 1610; el informe de Francisco Fabián y Fuero del año 1791; las Observaciones sobre la Historia Natural, Geografía, Agricultura, población y frutos del reyno de Valencia (1795-1797) del valenciano Antonio Josep Cavanilles; el Itinéraire descriptif de l'Espagne (1809) del viajero francés Alexandre de Laborde o las aportaciones de botánicos como el Voyage botanique dans le midi de l'Espagne de 18391845 escrito por el suizo Pierre-Edmond Boissier (1810-1888), o Excursions botaniques en Espagne (1884-1888) del francés, Georges Rouy (1851-1924). Ya en el siglo XX, Ifach aparece mencionada y dibujada en el Catálogo Monumental de España que redacta Manuel González Simancas entre los años 1907-1908. También podemos encontrar referencias en la enciclopédica Geografía General del Reino de Valencia coordinada por Francisco Carreras Candi y publicada a partir del año 1914 y en La antigua civilización ibérica del Reino de Valencia, publicado en el año 1918 por Francisco Almarche y Vázquez (1875-1927). Pero sin duda, el siglo XX será la centuria que nos traerá los primeros trabajos arqueológicos vinculados a la identificación de Ifach con la desaparecida colonia griega de Hemeroskopeion, como el elaborado por el arqueólogo americano Rhys Carpenter, quien plasmó sus investigaciones sobre la roca calpina en un artículo en el Butlletí de l'Associació Catalana d'Antropologia (1925: 187-193). Su testigo lo recogerá el reconocido prehistoriador alemán Adolf Schulten, quien acompañado por el geógrafo germano Otto Jessen y el académico Francisco Martínez y Martínez, realiza-
} 
arqueológica en el yacimiento, con resultados que ya han sido expuestos en diferentes trabajos monográficos (MENÉNDEZ FUEYO, 2008: 57-74; 2009: 153-193; Menéndez, Ferrer, Pina, 2012: 209-225) y que han culminado con la reciente presentación de la primera monografía del yacimiento (MENÉNDEZ FUEYO et alii, 2018a). Además de estos trabajos de carácter general, también hemos tenido ocasión de presentar una primera aproximación al estudio del registro material de los niveles de fundación de la pobla (MENÉNDEZ FUEYO, PINA MIRA, 2017: 101-133), que ha sido completada con la primera propuesta de seriación formal del repertorio cerámico decorado del yacimiento (MENÉNDEZ FUEYO, PINA MIRA, 2018: 179-220).

A pesar de que este trabajo tiene como objetivo mostrar el estudio de un registro material muy concreto localizado en el yacimiento, conviene que recordemos que, en la actualidad, no existe ningún proyecto arqueológico en toda la Comunidad Valenciana que permita desarrollar una investigación de esta época histórica tal y como lo permite la pobla medieval de Ifach. Casi todas las ciudades actuales que pueblan el territorio alicantino han sido fundadas, de una forma u otra, en la misma época que Ifach. Desde las más cercanas como Denia, Pego, Xàbia, Teulada, Callosa d'Ensarrià, pasando por La Vila Joiosa o la mismísima Benidorm, todas han sido fundaciones cristianas entre los siglos XIII y XIV. Como todas ellas Ifach, nace sobre el pergamino como un asentamiento de carácter urbano bajo el término de villa promovido inicialmente por iniciativa del rey Pedro III en 1282 bajo la fórmula: "...concedimus et damus vobis licenciam et plenum posse faciendi et construhendi de novo populacionem seu villam in loco vocato Ifach..."3, al enviar a Arnau de Mataró, de linaje y procedencia catalana, como lokator con el encargo de realizar la división y el reparto de casas, solares y espacios.

Sin embargo, para registrar su auténtica fundación deberemos esperar al reinado de Jaime II, en concreto al año 1297 a la orden ${ }^{4}$ que recibe el almirante de origen calabrés Ruggiero di Lauria, señor de Ifach desde ese año y, sobre todo, de Saurina de Entenza, su segunda mujer, que ejercerá de heredera universal en la minoría de sus hijos y como señora in pectore hasta su muerte en 1325

Ifach es importante por contar con un recinto amurallado prácticamente completo extendido por una superficie de unas 4 hectáreas, del que conservamos más de 1000 metros lineales de muralla, siendo el área Norte (Figura 3), la que se encuentra en mejor estado, con 400 metros de perímetro conservado y ocho torres en saliente, con una anchura que ronda los 1,30 metros y con alzados con una altura conservada superior a los seis metros. Ifach cuenta además con un complejo sistema de ingreso, con tres puertas, corredor cubierto, cámara de seguridad y torre de guardia, que nos habla de una poliorcética planificada y pensada, aunque realizada en fases progresivas hasta su acabado final. Pero, sobre todo, nos habla de una obra presidida por un alto carácter defensivo o militar que impregna todo el conjunto,

rán visitas al Peñón de Ifach y a sus restos, cuyas conclusiones quedarán plasmadas en un artículo de académico oriundo de Altea publicado en 1928 en el Boletín de la Real Academia de la Historia (1928: 752-775). Testigo de estos trabajos también lo fue el presbítero y por entonces ya Director Honorífico del Museo Arqueológico Provincial de Alicante, Don José Belda Domínguez quien, a principios de los años 60 retorna a Ifach, realizando a su manera una serie de actuaciones en el Peñón cuyos materiales se encuentran actualmente en los almacenes del MARQ. Junto a estas intervenciones, también surge la cronística local, encabezada por el también presbítero Vicente Llopis Bertomeu, quien publica en el año 1954 una monografía sobre la villa de Calp con abundantes referencias a los restos de la pobla medieval. En tiempos más actuales, comienzan las intervenciones con un rigor científico procedentes del área universitaria, encabezadas por la Catedrática de Arqueologia de la Universidad de Valencia, Carmen Aranegui Gascó, quien realiza diversas actuaciones en la ladera del Peñón (1973: 49-69; 1986: 53-54; 1977: 51-59; 1978: 17-20) en las que levanta y publica, junto al arqueólogo medievalista André Bazzana, una planimetría del recinto amurallado de la pobla al que consideraron de época islámica (1980: 421-436). Previo al inicio de nuestro proyecto, la historiografía más actual nos trae referencias a la pobla en trabajos de insignes investigadores como Carmen Barceló Torres (1982), Francisco García García (1986: 167-174), Josep Ivars Pérez (1987: 35-42), Josep Torró Abad junto a Jose María Segura Martí (1991: 147-181), Jaume Pastor Fluixà y Julia Campón Gonzalvo (1990; 2005) o Basilio Pavón Maldonado (1997-1998: 81-105).

3. Archivo de la Corona de Aragón, Cancillería, Registro 46, folio 77r-v.

4. Archivo de la Corona de Aragón, Cancillería, Registro 25, folio 168v. 


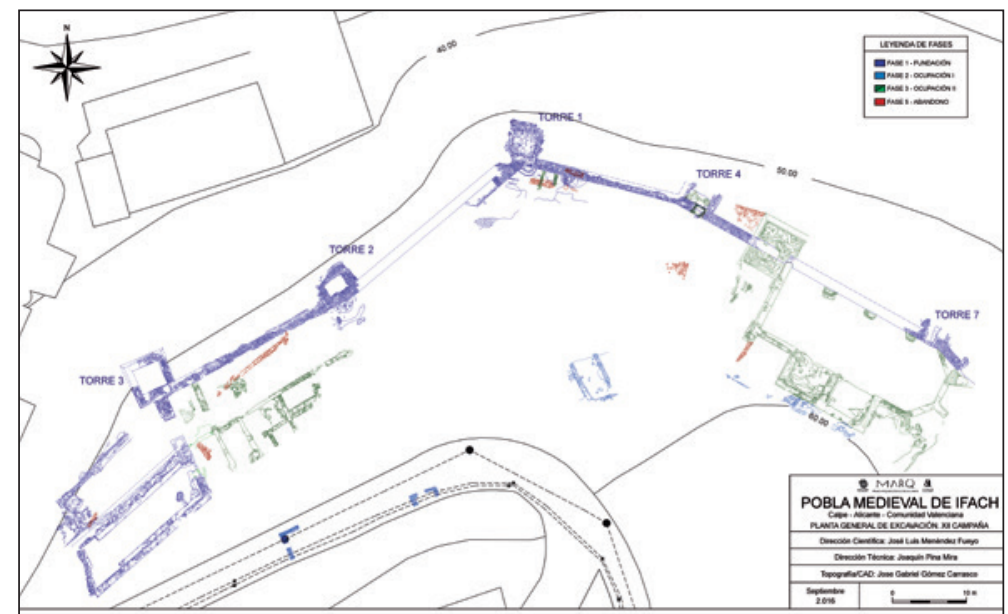

Figura 3. Planta de los restos del área norte del yacimiento de la Pobla de Ifach. Archivo Gráfico MARQ. Topografía: Aerograph Studio.

dicado al control del sistema de ingreso, al descanso de la tropa y a las labores domésticas en el que encontramos un banco corrido, un brasero y una pileta de piedra donde localizamos un cántaro fragmentado pero completo. El último sector de la planta baja parece dedicado a las tareas domésticas, donde hemos encontrado las pruebas de un posible hogar, así como la impronta y restos materiales de una tinaja de bodega rehundida en el pavimento. El piso superior, al que se accede de forma independiente a la

algo que hemos podido rastrear en todas las obras erigidas por todo el territorio de la Casa de Lauria en la primera mitad del siglo XIV, donde se superponen las necesidades defensivas a las residenciales otorgando a todas las obras una presencia monumental importante que sirve también de mensaje subliminal de la presencia en el territorio de un poder señorial fuerte, efectivo, sólido como sus defensas e impenetrable como sus puertas de acceso. Sobre el primer pavimento de la pobla hemos podido documentar una buena cantidad de hallazgos monetarios en contexto arqueológico que nos ofrecen una horquilla de fundación situada entre el final del siglo XIII y las primeras décadas del siglo XIV, horquilla cronológica coincidente con la orden de fundación expresada en segundo término al almirante Ruggiero di Lauria en el año 1297.

Bajo la tutela de la Casa de Lauria, Ifach termina sus murallas, su sistema de ingreso y, sobre todo, sus principales edificios, como el denominado Edificio 6, al que hemos denominado Domus Lauria (Figura 4), una impresionante construcción destinada a albergar el poder del señor de Ifach sobre la población del territorio, de $20 \times 6$ metros, dotado de dos plantas sostenidas por ménsulas de piedra y con una superficie interna que ronda los 100 metros cuadrados por planta. La planta baja parece tratarse de un cuerpo de guardia, de- planta baja, sabemos que estaba pavimentado con ladrillos sin decorar, dispuestos a soga. La sala contaba con, al menos, cuatro ventanales de los que hemos podido reconstruir su configuración gracias a los hallazgos arqueológicos de estos últimos años.

Por ello, sabemos que el edificio contaba en esta planta con ventanas ajimezadas de arco de medio punto y treboladas, dispuestas alternativamente de este a oeste. Las excavaciones de 2016 permitieron recuperar un capitel y su imposta, así como todo el parteluz y alféizar de una de ellas. El descubrimiento del capitel ha sido, sin duda, uno de los grandes hallazgos realizados en la pobla de Ifach (MENENDEZ FUEYO, 2018), con una cronología, situada en

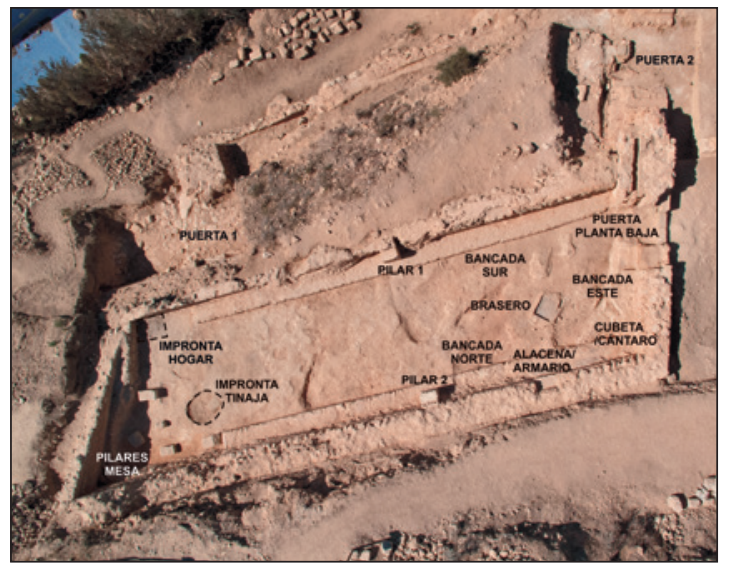

Figura 4. Planta de la Domus Lauria. Archivo Gráfico MARQ. 
la primera mitad del siglo XIV, que permite vincularlo con la fase de fundación de Ifach bajo el mandato de Saurina de Entenza.

Pero la importancia de los restos excavados en Ifach no solo se limita a la arquitectura defensiva y nobiliar. La excavación entre los años 2008-2013 de los restos de una gran iglesia medieval (Figura 5), permitió exhumar uno de los edificios religiosos más antiguos de la comarca, cuyas fechas de construcción tenemos perfectamente documentadas gracias a secuencia constructiva de los paramentos que indican que se trata de una obra posterior a la construcción de las murallas, ya que los muros de la iglesia se incrustan literalmente en el intradós de la muralla de Ifach. Lo sabemos también por las dataciones de ${ }^{14} \mathrm{C}$ de los enterramientos de la necrópolis que rodean al edificio, que han ofrecido unas horquillas cronológicas específicas situadas entre los años 1300-1370 y por el hallazgo sobre el pavimento de la Capilla Sur 2 de un croat de plata del reinado de Alfonso IV el Benigno que nos ha ofrecido una datación post-quem que sitúa la construcción en la horquilla cronológica de 1329-1336, por lo que podemos situar la construcción del edificio en la primera mitad del siglo XIV, bajo el auspicio de la hija del almirante, Margarita de Lauria y Entenza, señora de Ifach entre 1325-1344.

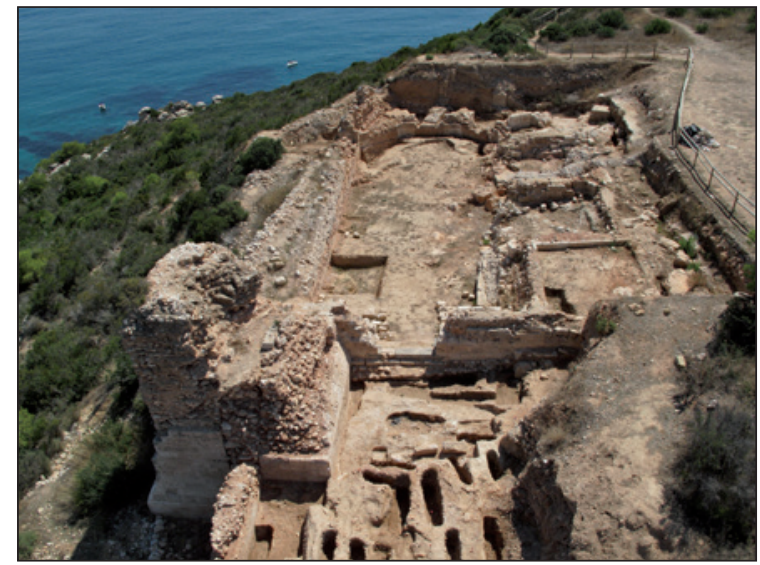

Figura 5. Vista panorámica de los restos de la Iglesia medieval de la Pobla de Ifach. Archivo Gráfico MARQ.

\section{EL CÁLIZ Y PATENA DE IFACH EN SU CONTEXTO ARQUEOLOGICO. EL CIMITERIUM MEDIEVAL}

La aparición de los objetos sometidos a estudio en este artículo debemos situarla en el interior de una de las tumbas que se encuentran diseminadas, con cierto orden, desde la puerta de ingreso a la iglesia medieval (Figura 6), extendiéndose in circuitu ecclesiae, hasta alcanzar los triginta passuus ecclesiasticos -30 pasos de distancia- que convierten nuestro espacio en un cimiterium, términos utilizados de forma habitual en el área catalana y provenzal, con el que se denominan a aquellas áreas delimitadas, sacralizadas, pacificadas, protegidas y jurídicamente definidas, cedidas por la Iglesia bajo la fórmula "...ut intra spacium et sacraria fierent et mortui homines requiescerent..." (ORDEIG I MATA, 1989: 260). Enterrados en tierra bendecida, los muertos gozaban además del hecho de estar ad sanctos, o sea, próximos al santo cuyas reliquias estaban depositadas en el altar, y el cual aseguraba la paz y protección de los difuntos, prometiéndoles su intercessio en el día del Juicio Final.

Desde que en la IV Campaña de excavaciones realizada en el año 2008 localizamos la primera de las tumbas delante de la fachada principal de la iglesia medieval de Ifach (ME-

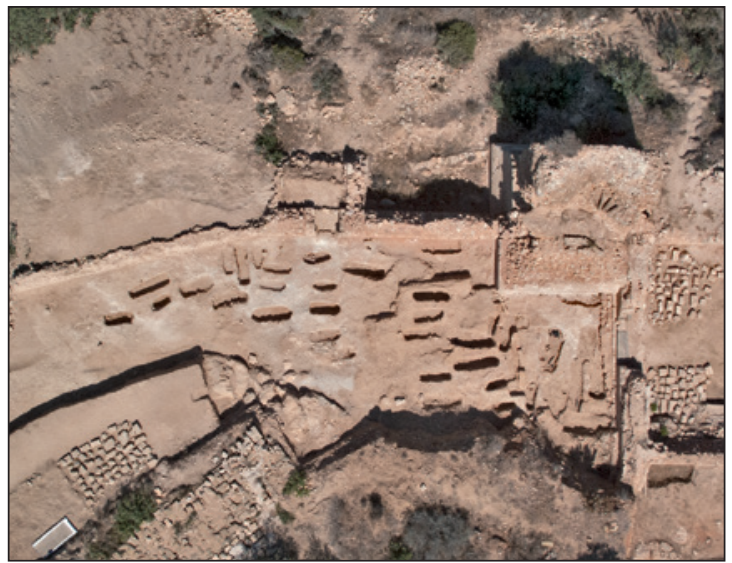

Figura 6. Vista cenital del área funeraria o cimiterium junto a la fechada de ingreso de la iglesia de Ifach. Archivo Gráfico MARQ. 
NÉNDEZ FUEYO, 2009: 188), el área del cimiterium no ha dejado de crecer y ampliarse en las sucesivas campañas, convirtiéndose en un sector fundamental y de obligado estudio para todos los que componemos el equipo de investigación (MALAGUTTI, FERRER, MENÉNDEZ, 2013: 18-19; MALAGUTTI, MENENDEZ, PINA, 2018: 145-178).

La actual población documentada en el cimiterium de Ifach se situa en una muestra de individuos pertenecientes a 59 tumbas halladas y excavadas y correspondiente a un número mínimo de 72 individuos. Se trata de 58 individuos relativos a 52 sepulturas primarias -individuales o múltiples- y reducidas en fosa simple, mientras que 14 corresponden al número mínimo de individuos de una inhumación secundaria múltiple de la tumba T20.

Esta diferencia llamativa entre el número de fosas y de individuos tiene su explicación en la existencia de una gestión y organización, no solo del espacio funerario útil, sino también de la calidad espacial del interior de las tumbas. Cada cierto tiempo, las tumbas parecen renovarse, desplazando cuerpos para colocar a otros fallecidos. En algunos casos, como en las T2, T7, T22, T23, T32, T40, T41 y $\mathrm{T} 42$, las tumbas han aparecido completamente vacías, mientras que las T21, T28, T27, T37, T38 y T43 aparecen con algún hueso de dedo o de pie que había quedado en la fosa cuando se produce el levantamiento del cadáver post-inhumación. En otros casos, como en la imponente T20, hemos encontrado 16 cuerpos colocados sobre un enterramiento primario, generando una cripta múltiple u osario. Esta acción lo que nos revela es la interesante necesidad de vaciar otras tumbas individuales, guardando los cuerpos levantados en una sola tumba, para generar espacios vacíos. Todas estas acciones creemos que parten de un control y organización de lo que es el espacio funerario.
Los enterramientos del cimiterium muestran un intervalo temporal que hemos obtenido a partir de 17 dataciones radiocarbónicas ${ }^{5}$ practicadas sobre muestras de registro óseo procedentes de buena parte de las inhumaciones descubiertas en el área funeraria. Hasta el momento, han ofrecido una horquilla cronológica situada entre los años 1296-1412, con una calibración conjunta BCAL situada entre los años 1300-1370 (Figura 7). El uso de estas

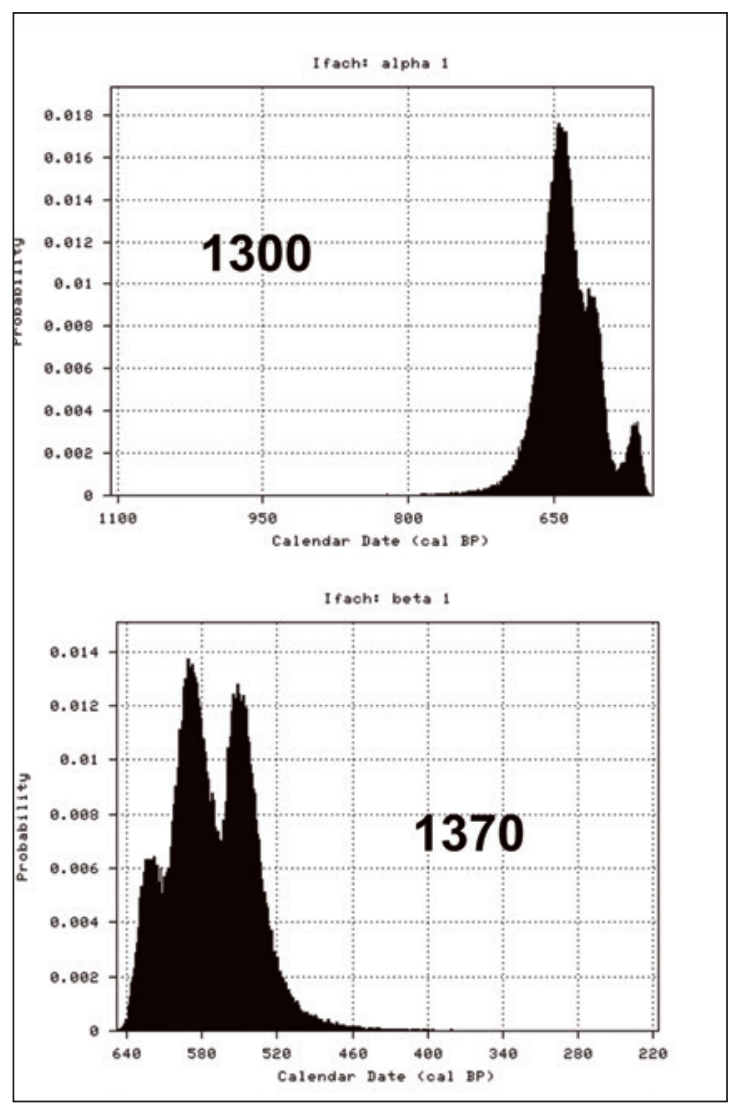

Figura 7. Calibración conjunta BCAL calculada a partir de las analíticas de 14C establecidas por las muestras de registro óseo del cimiterium de Ifach que sitúa en período de ocupación del yacimiento entre los años 1300-1370. Archivo Gráfico MARQ.

fechas sometidas a calibración bajo los principios de la estadística bayesiana, supone para la arqueología medieval una revalorización de la estratigrafía como herramienta de informa-

\footnotetext{
5. Las dos primeras fueron encargadas a los laboratorios DATA situado en Miami (USA) con la intermediación de la empresa de arqueología ARQUEALIA. Mientras que las 15 dataciones restantes han sido realizadas en el Centro Nacional de Aceleradores (CNA) ubicado en Sevilla y dependiente del Consejo Superior de Investigaciones Científicas.
} 
ción cronológica para la interpretación histórica. Es interesante destacar que las dataciones presentan una gran homogeneidad, sin que se perciban graves desviaciones entre las muestras analizadas. También es importante precisar que no abundan las dataciones de este tipo en contextos arqueológicos bajomedievales con lo que la trascendencia de estas fechas incrementa el valor de los datos obtenidos. Las fechas que ofrecen las dataciones radiocarbónicas muestran intervalos, no fechas precisas.

La correspondencia de una fecha obtenida por el método del ${ }^{14} \mathrm{C}$ con la fecha real en la que se produjo el acontecimiento al que se asocia la muestra datada -en nuestro caso, los enterramientos del cimiterium- se expresa en términos de probabilidad estadística, de manera que las fechas que delimitan el intervalo -fecha más antigua y reciente-poseen, al igual que el resto de las que se sitúan entre ellas, una probabilidad de fecha real como hemos podido comprobar en otros yacimientos aunque no sean de época medieval (JOVER MAESTRE, LÓPEZ PADILLA, GARCÍA-DONATO, 2014: 384). Ahora bien, la estratigrafía no aporta fechas, pero sí permite establecer con precisión qué acontecimientos se produjeron con un ante quem y un post quem. O lo que es lo mismo, posibilita establecer un orden secuencial inequívoco en la conformación de los depósitos sedimentarios. Como toda aproximación, los actuales datos pueden ser modificados e incluso matizados, cuando contemos con un mayor número de dataciones que pertenezcan a una misma fase de ocupación, permitiendo que una calibración conjunta más afinada.

Sin entrar en valoraciones más profundas, que han sido parte de un análisis más detallado en fechas muy recientes (MALAGUTTI, MENÉNDEZ, PINA, 2018: 145-177), el estudio de los restos del cimiterium de Ifach marca uno de los axiomas fundamentales para el estudio del yacimiento: Los habitantes de Ifach fueron sus constructores, un planteamiento de partida por el que comenzamos a saber que buena parte de los desgastes óseos, artrosis y estenosis múltiples que presentan los más de 80 individuos encontrados en las fosas de las tumbas de Ifach, parecen ser producidos por acciones de fuerza muy intensa y sostenida en el tiempo que asociamos inicialmente con esa mano de obra desprovista de experiencia y práctica en la construcción, como son los braceros, peones y ayudantes que toda construcción precisa.

Algunos de estos individuos documentados fueron enterrados con ropa -generalmente hebillas- que demuestran la existencia de ciertos elementos de vestuario y calzado. Sin embargo, la inexistencia de ajuar y elementos de acompañamiento es el rasgo fundamental de la mayoría de los enterrados. Las pruebas arqueológicas nos plantean la posibilidad de que los cuerpos fueran desnudos, siendo cubiertos únicamente con una mortaja, como hemos podido documentar en diferentes restos óseos que llevan adheridos a los huesos fragmentos de tela. En este sentido, los análisis realizados en el Instituto de Materiales (IUMA) del Departamento de Química Inorgánica de la Universidad de Alicante por los profesores David Cazorla Amorós, Isidro Martínez Mira y Enrique Vilaplana Ortego han revelado que los fragmentos de la mortaja mostraban un hilado de algodón.

\section{LA TUMBA 13 DEL CIMITERIUM MEDIEVAL DE IFACH}

Sin embargo, dentro del contexto del área funeraria, existe una excepción, una tumba que nos ha mostrado uno de los hallazgos más singulares y destacados de los que hemos tenido el privilegio de asistir y que tuvo lugar durante la campaña de 2009 en el área funeraria. Este descubrimiento se realizó en la denominada T13 (Figura 8), una tumba adosada al extradós de la iglesia medieval, en una fosa de forma alargada con los extremos redondeados. En el interior de la misma aparecieron los restos del cadáver de género masculino, en un estado de conservación deficiente y del que, tras su excavación, se concluyó que presentaba unas características rituales diferentes de las del resto de inhumaciones de la necrópolis (Figura 9). En concreto, llamaba la atención el tamaño y la dimensión de los huesos responden a los 


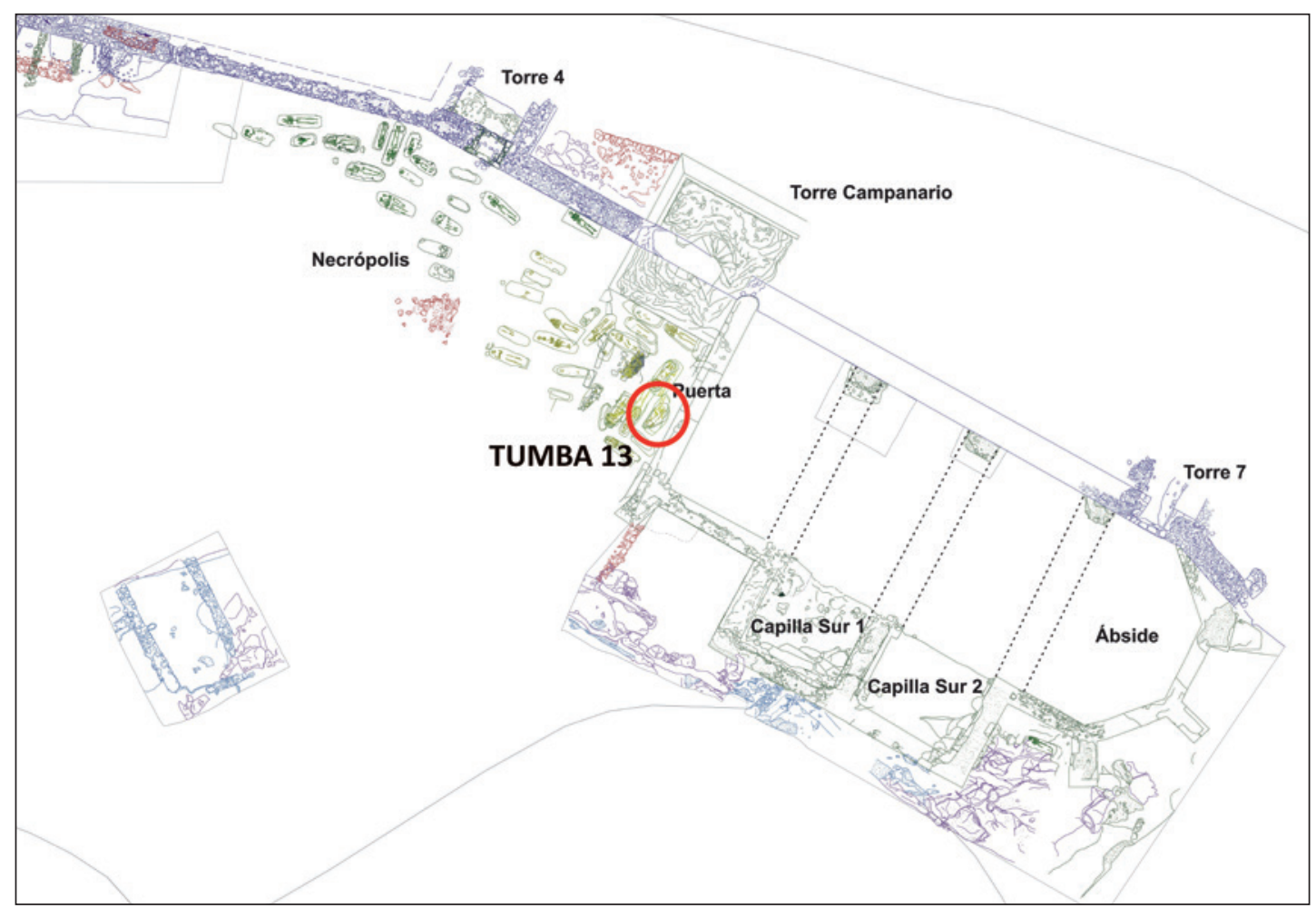

Figura 8. Planta del cimiterium con la localización de la Tumba 13. Archivo Gráfico MARQ. Topografía: Aerograph Studio.

de un individuo poco robusto y grácil, gracias a detalles como el que se aprecia en el borde de la rama inferior de la mandíbula, donde no presenta una marcada forma cuadrangular ni particularmente gruesa. Por otro lado, el hueso sacro es largo, estrechado y alto; los huesos coxales resultan altos y estrechos, con relevos marcados y la escotadura ciática mayor parece pertenecer al grado 3 de Buikstra-Ubelaker. Todos ellos son parámetros que podrían apuntar a rasgos posiblemente masculinos.

En cuanto a su edad y atendiendo a sus caracteres morfométricos relacionados con su epífisis medial de la clavícula derecha, que se encuentra en avanzado estado de soldadura y por el tramo de la sutura sagital conservada, se podría determinar un arco de edad situado entre los 20-25 años. Comparando con la media de edad de la población de la necrópolis, que se encuentra en el umbral de los 20-21 años, podríamos decir que es un individuo que ha superado ligeramente su periodo de vida.
Esta afirmación se refuerza si aportamos el estudio maxilo-dental, donde se evidencian discretos niveles de desgaste, sobre todo en cuanto a los incisivos superiores e inferiores. Eso sí, aparecen lógicas evidencias de banda de hipoplasia del esmalte en cuanto a los caninos y premolares inferiores, que permiten plantear la hipótesis de que el individuo sobrevivió a un episodio de estrés durante la infancia. Además, los procesos degenerativos son escasos en comparación con otras inhumaciones del cimiterium donde las degeneraciones musculares son muy evidentes. En este caso, las analíticas detectan alguna leve entesopatía en el radio derecho, con entesofitos y erosión a la altura de la inserción del músculo bíceps y una posible artrosis localizada en el ámbito de la falange distal del pie izquierdo.

El sujeto se encontraba en deposición primaria, en decúbito supino, con la cabeza ligeramente doblada a la izquierda, los brazos doblados sobre el vientre formando un ángulo obtuso, con las piernas estiradas y paralelas 


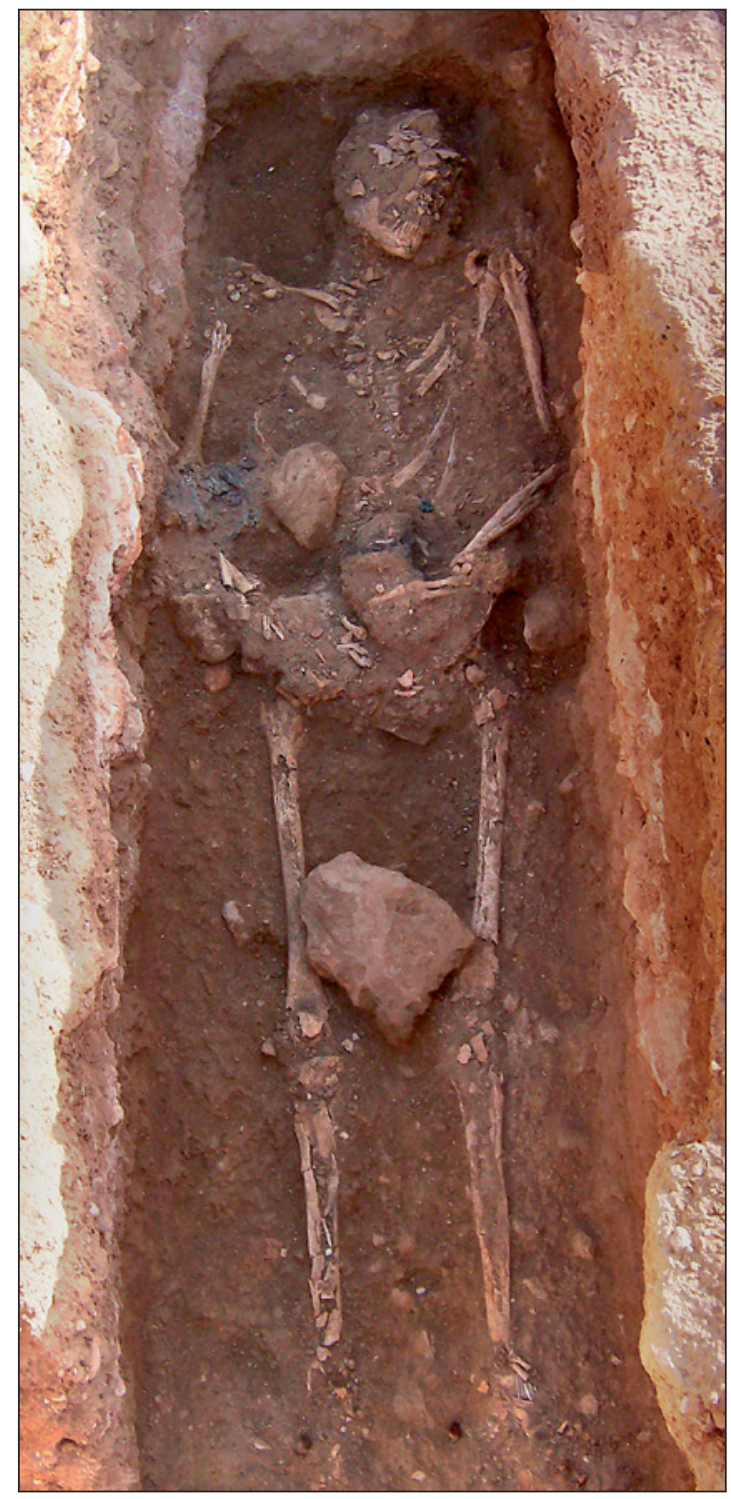

Figura 9. Imagen de la Tumba 13 recién excavada. Archivo Gráfico MARQ.

entre sí (Figura 10). El análisis antropológico ha determinado que la descomposición tuvo lugar en espacio abierto, ya que la mandíbula no se había abierto. Además, las costillas y la articulación clavícula - esternón se muestran laxas, o sea, se han mantenido en posición, aunque se hayan alejado ligeramente. Los fémures no se han girado y aparecen conservados en su posición original, mientras que los coxales no muestran abiertos, aunque sus jefes hayan doblado hacia un lado, pero no hacia delante, una situación que los especialistas consideran típica de una descomposición en espacio

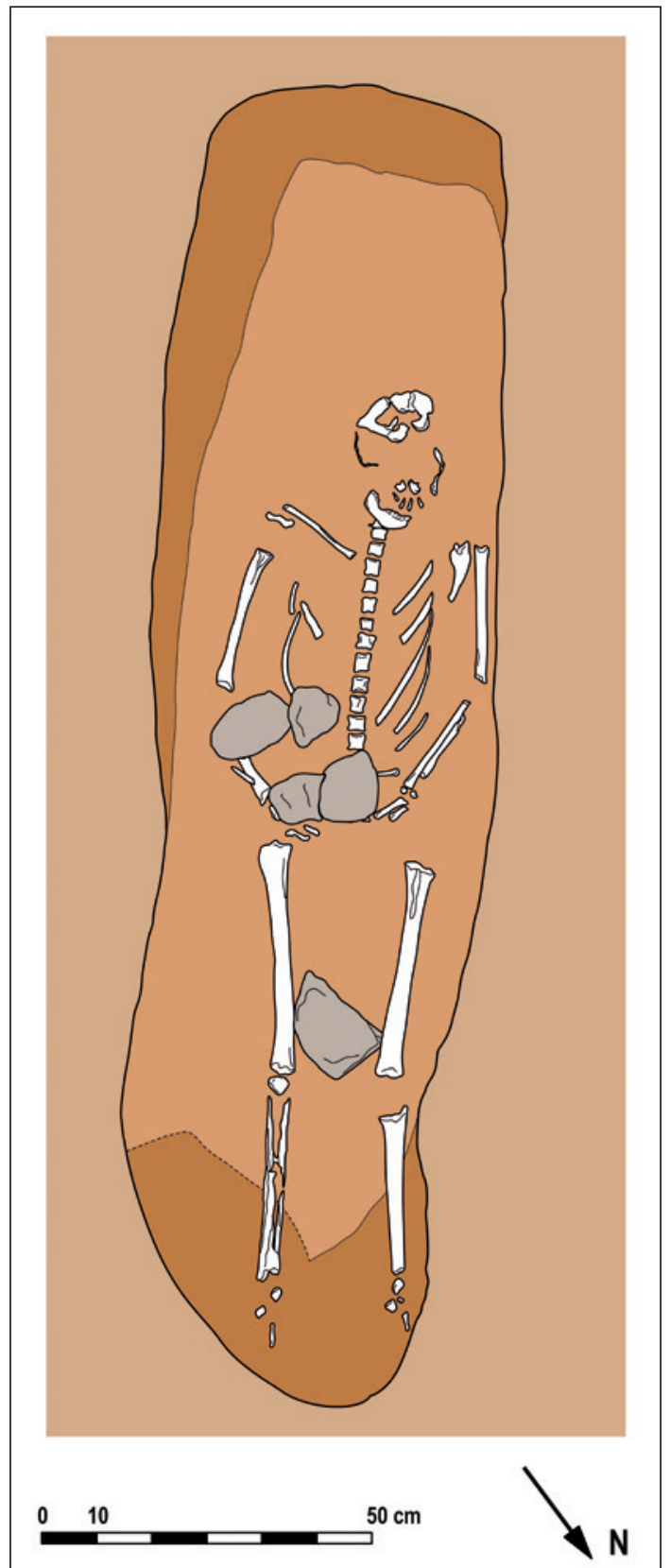

Figura 10. Planta de la Tumba 13 con la localización de las piedras dispuestas para la inmovilización del inhumado. Dibujo: Pilar Mas Hurtuna. Archivo Gráfico MARQ.

abierto. Solo los hombros aparecen ligeramente comprimidos por las paredes de la fosa, que resulta más estrecha en la parte superior.

Otro aspecto interesante que se observa en la voluntad manifiesta de inmovilizar la posición del difunto con particular referencia a la cabeza y a los brazos ha sido registrado en nu- 
merosos casos ( $\mathrm{T} 1, \mathrm{~T} 4, \mathrm{~T} 11, \mathrm{~T} 13, \mathrm{~T} 34, \mathrm{~T} 35, \mathrm{~T} 51)$. Según el trabajo de Enrique Gutiérrez Cuenca sobre los cementerios de Cantabria (2015), las piedras bajo el mentón o sobre el pecho aparecen en varias necrópolis del norte de España, como en Soria en El Soto de Garray (MORALES HERNÁNDEZ, 1991), San Martín de Rejas de San Esteban y Nuestra Señora de la Concepción de Omenaca (CASA MARTíNEZ, 1992) o Tiermes, donde se documentan una veintena de casos, "siempre asociadas a tumbas de lajas y en cronologías en torno al siglo XII y posteriores" (CASA MARTÍNEZ, 1994: 89).

En Guipúzcoa, donde hay algunos ejemplos de estructuras para la sujeción del cráneo asociadas a tumbas de fosa simple se encuentra también la colocación de una piedra bajo la barbilla en San Miguel de Irura, en una sepultura datada por $\mathrm{C}^{14}$ hacia comienzos del siglo XV (SARASOLA ETXEGOIEN, 2011). También se ha documentado el mismo tipo de enterramiento en Navarra (VALLE DE TARAZAGA, BONTHORNE, 2016: 233-245) para un cementerio medieval entre los siglos VII-X en relación a una mansio romana. Por lo que concierne a la inmovilización del cráneo, parece bastante razonable relacionar este aspecto del gesto funerario con la intencionalidad de que la mandíbula se quedase cerrada y no se abriera durante la descomposición (CASA MARTíNEZ, 1994; DOMÍNGUEZ BOLANOS, 2003). Además, ya que en Ifach parece realizarse también en relación a la posición de los brazos no resulta atrevido pensar que esta práctica siga esta función en la que se consigue inmovilizar la posición del individuo.
No obstante, el cuidado que parece haberse empleado en algunos casos en lograr la inmovilización de la cabeza, o en conseguir que quede protegida, marcando con dichas piedras la existencia de elementos diferenciadores que elevarían la importancia social del individuo. Esta manera colocación del cuerpo es un procedimiento habitual documentado en muchas tumbas de necrópolis medievales peninsulares (GUTIÉRREZ CUENCA, 2015: 587588), sobre todo frente a un modelo de gestión del espacio funerario donde se producen una continua alteración y remoción del interior de las fosas como estrategia de gestión de un espacio funerario de carácter finito.

Por otro lado, la documentación arqueológica ha revelado que se trataba de un individuo que había sido enterrado vestido, algo muy diferente del que ocurre con la mayor parte de la población exhumada en la necrópolis ifacense, los cuales suelen aparecer nudo y amortajados. En el caso de la T13, se pudo identificar gracias a la aparición, cerca de la cadera y sobre cada uno de los pies del enterrado, de unas hebillas de bronce que correspondían, en el primer caso, con un cinturón y, en el segundo, con los vínculos de algún tipo de calzado que vestía el individuo en el momento de su inhumación (Figura 11).

Otro detalle importante que revela el análisis es que la articulación de ambas manos se ha mantenido en su posición original. La puntual presencia de una piedra bajo la mano derecha y en el medio de las piernas sugiere que pudieran haber servido para sujetar e in-

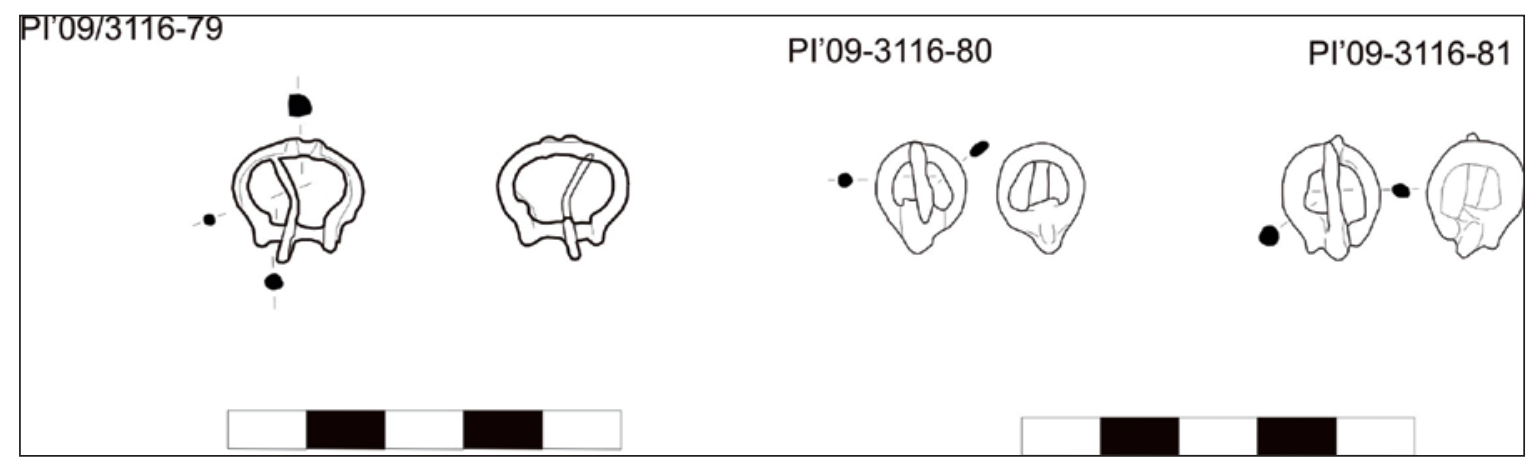

Figura 11. Hebillas de cinturón y de calzado halladas en el interior de la Tumba 13. Archivo Gráfico MARQ. 
movilizar al individuo en la posición deseada, ya que resultan de tamaño considerable como para ser solo parte del relleno y situadas en una posición útil para consolidar la colocación del difunto. Si nos detenemos concretamente en la mano derecha, apreciamos que aparece simplemente apoyada en la cadera, mostrando un objeto de forma ovoide ${ }^{6}$ a la altura del antebrazo derecho mientras que en la mano izquierda se aprecia que sujeta un objeto indeterminado ${ }^{7}$ sobre el estómago (Figura 12).

Después de los estudios pertinentes realizados por los profesores David Cazorla Amorós, Isidro Martínez Mira, Enrique Vilaplana Ortego y Olga Cornejo Navarro del Instituto de Materiales (IUMA) ${ }^{8}$ del Departamento de Química Inorgánica de la Universidad de Alicante (UA), los objetos indeterminados sostenidos por la mano izquierda y el antebrazo han sido identificados como los restos de un nudo medial cuadrilobulado perteneciente al pie de un cáliz litúrgico y a los restos de una patena.

\section{EL CÁLIZ Y LA PATENA DE IFACH}

Respecto al cáliz, los fragmentos analizados $^{9}$ muestran una altura total conservada de $5,63 \mathrm{~cm}$., con un diámetro máximo de la zona esférica cuadrilobulada de $3,89 \mathrm{~cm}$, un diámetro de la zona circular plana de contacto de

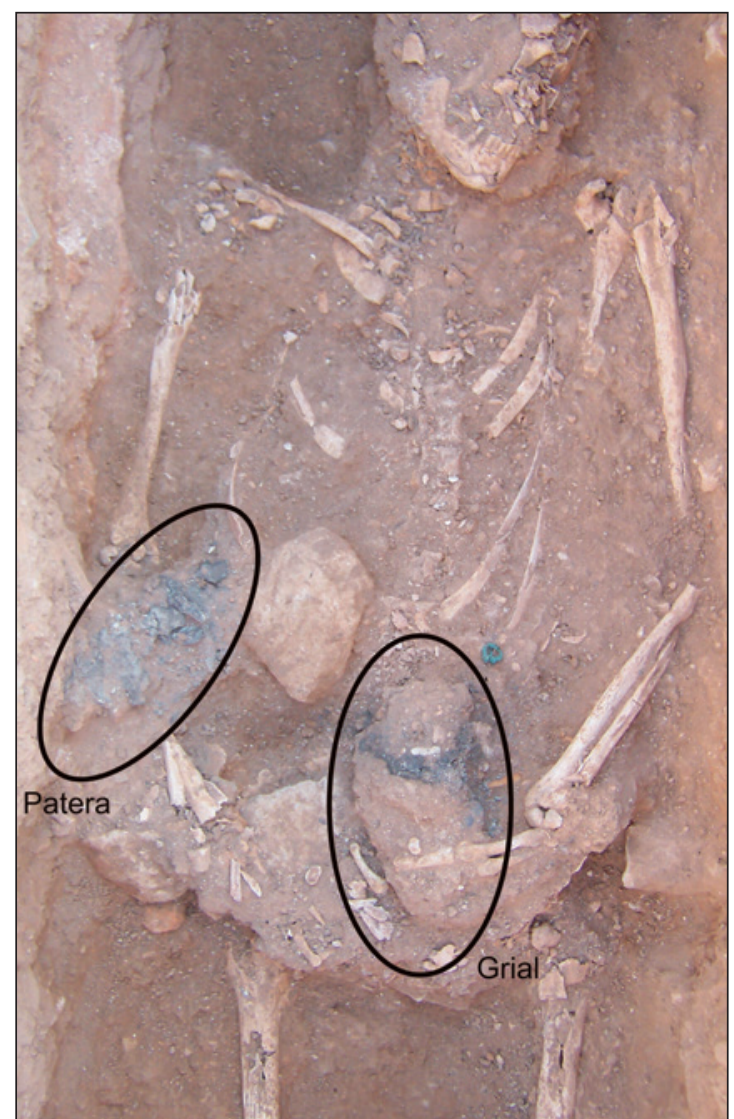

Figura 12. Localización de los restos del cáliz y la patena en el interior de la Tumba 13. Archivo Gráfico MARQ.

1,90 cm y un peso de 222,64 gramos (Figura 13 y 14). Gracias a la imagen que muestra la Figura

6. La pieza lleva por signatura PI'09/3116-77.

7. La pieza lleva por signatura PI ’09/3116-78 y número de Catálogo Sistemático del MARQ 15980.

8. Todas las referencias técnicas de las piezas han sido entresacadas del estudio técnico realizado y firmado por los profesores David Cazorla Amorós, Isidro Martínez Mira, Enrique Vilaplana Ortego y Olga Cornejo Navarro por encargo de la dirección arqueológica del proyecto en la Pobla de Ifach y subvencionado a cargo del presupuesto del Plan de Excavaciones Arqueológicas del ejercicio 2014 de la Diputación de Alicante. Agradecemos a los miembros del Instituto de Materiales (IUMA) y a los profesores citados toda su implicación, colaboración e interés mostrados con las piesas y que la investigación arqueológica en el yacimiento. Por ende, queremos también agradecer a J. Bautista Herrera, J. Bautista Peña, A. Jareño, personal de los Servicios Técnicos de Investigación de la Universidad de Alicante, su ayuda a la hora de realizar los análisis de las muestras.

9. Para la documentación digital de ambas piezas se ha utilizado una cámara digital reflex Canon 550D. En el caso del cáliz, se ha empleado para su documentación la técnica de microfluorescencia de Rayos X ( $\mu$ FRX) para saber su composición preservando su integridad con un equipo Orbis Micro-XRF Analyzer de EDAX. Por el contrario, el deficiente estado de conservación de los posibles restos de la patena posibilitaron la realización de análisis mediante Fluorescencia de rayos X (FRX) con un equipo Phillips Magic Pro equipado con un tubo de rodio y una ventana de berilio y un espectrómetro secuencial modelo PW2400; una Difracción de Rayos X (DRX) con un equipo Miniflex II de Rigaku, equipado con un generador de rayos Toshiba A-20,41, usando una radiación Cu Ka $(\lambda=1.54 \AA)$, con una energía de $30 \mathrm{kV}$ y $15 \mathrm{~mA}$ de corriente. El rango de amplitud fue de 4 a 70 grados $2 \theta$, con un paso angular de 0.025 grados $2 \theta$ y un tiempo de paso de 3 segundos. Los análisis se realizaron a una temperatura ambiente de $25^{\circ} \mathrm{C}$. y una Microscopía Electrónica de Barrido (SEM-EDX) un equipo Hitachi S-3000N equipado con un detector de electrones secundarios tipo centelleador-fotomultiplicador con una resolución de 3,5 nm, un detector de electrones retrodispersados tipo semiconductor con resolución de 5 nm y un detector de rayos X (EDS) tipo XFlash 3001 de Bruker capaz de detectar elementos químicos de número atómico comprendido entre los del carbono (C) y el uranio (U). La energía del haz de electrones utilizada fue de $20 \mathrm{KeV}$ por lo que los resultados obtenidos en este caso fueron más completos. Todos los equipos utilizados en los análisis pertenecen al Departamento de Química Inorgánica y a los Servicios Técnicos de Investigación de la Universidad de Alicante a quienes agradecemos el interés y colaboración mostrados en todo el proceso de investigación. 
PI'09/3116-1
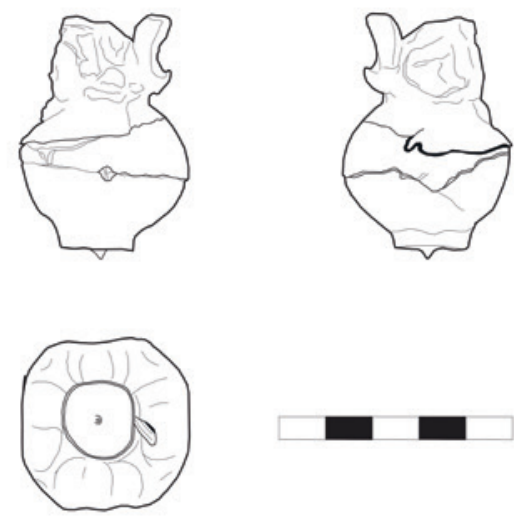

Figura 13. Dibujo de los restos del nudo medial del cáliz de Ifach. Dibujo: Roberto Ferrer Carrión. Archivo Gráfico MARQ.

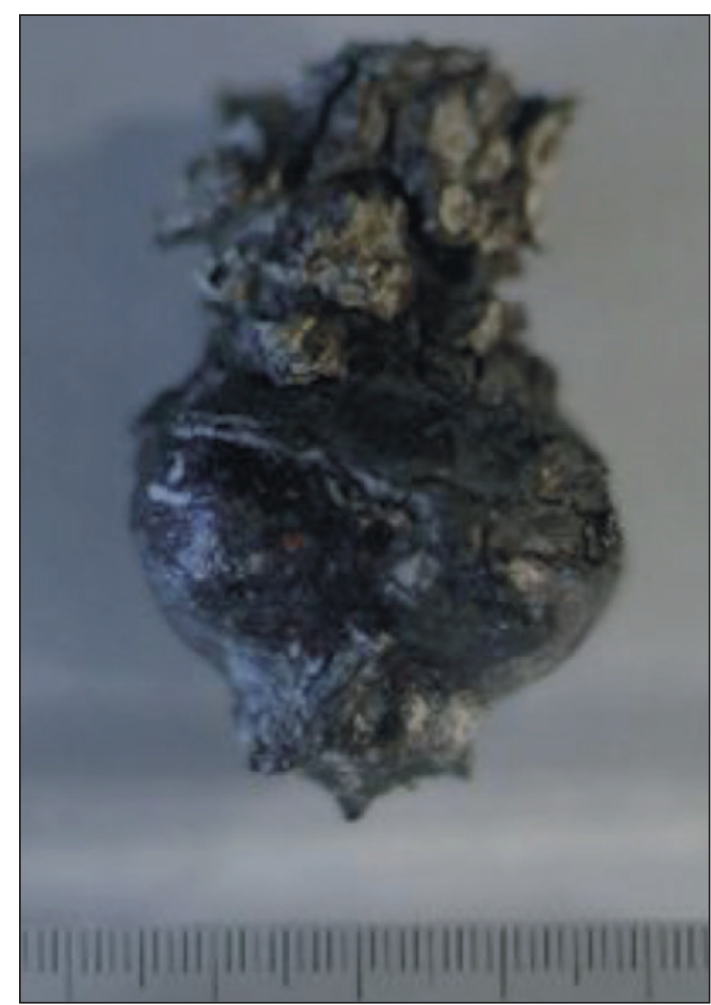

Figura 14. Imagen del nudo medial del cáliz de Ifach. Archivo Gráfico MARQ.

14 podemos observar que no hay muchos elementos que permiten discernir cuál es su parte superior y cuál la inferior. Morfológicamente,

en uno de los extremos de la pieza aparece una parte más o menos plana con dos pívots que se corresponderían con los arranques de dos de sus lóbulos, los otros dos no presentan estos vástagos tan pronunciados. Así mismo, recubriendo la parte superior del nudo tetralobular, aparece una lámina de color grisáceo y sobrepuesta a esta lámina, hay otra de color más claro, que cubre una extensión menor con fracturas. Finalmente, en el otro extremo hallamos un amasijo informe, con una coloración más clara y una apariencia poco compacta con presencia de grandes grietas, que seguramente se correspondería con una pieza que conectaría el nudo, bien con la copa o bien con el pie.

Recubriendo la parte superior del pomo cuadrilobulado y alguna de las zonas inferiores se encuentra una lámina de su mismo color y sobrepuesta a ella aparece otra que cubre una extensión menor y que muestra fracturas siendo su color un poco más claro que la capa infrayacente. Por último, en el extremo opuesto del que acabamos de describir aparece un amasijo informe, con una coloración más clara y una apariencia poco compacta con presencia de grandes grietas que seguramente se correspondería con el resto del ástil que conectaría el pomo con el pie y que tendría una composición diferente dado su grado de corrosión y su diferente coloración.

A la vista de la reconstrucción planteada (Figura 15), creemos que el desarrollo del cáliz debería acercarse al tipo de copa, situado entre los tipos CC1 al CC6 de la tipología del estudio de Lourdes de Sanjosé Llongueras (2015: 1602), cuyo nudo medial se encuentra conectado directamente con el pie de tipo triangular y el recipiente, seguramente de forma hemiesférica. Tal y como ha puesto de relieve el estudio de los restos, su forma se acercaría a piezas como los cálices de Sant Ermengol, Sant Salvador de Vedella, Arnau de Creixell o del obispo Guillem de Cabanelles. De esta forma, debemos desechar la opción de que el nudo medial conecte con un vástago intermedio, al estilo de algunos cálices como los de Sant Bernat Calbó, Sant Andreu de Llavaneres, Bernat de Olivella o Núria. 


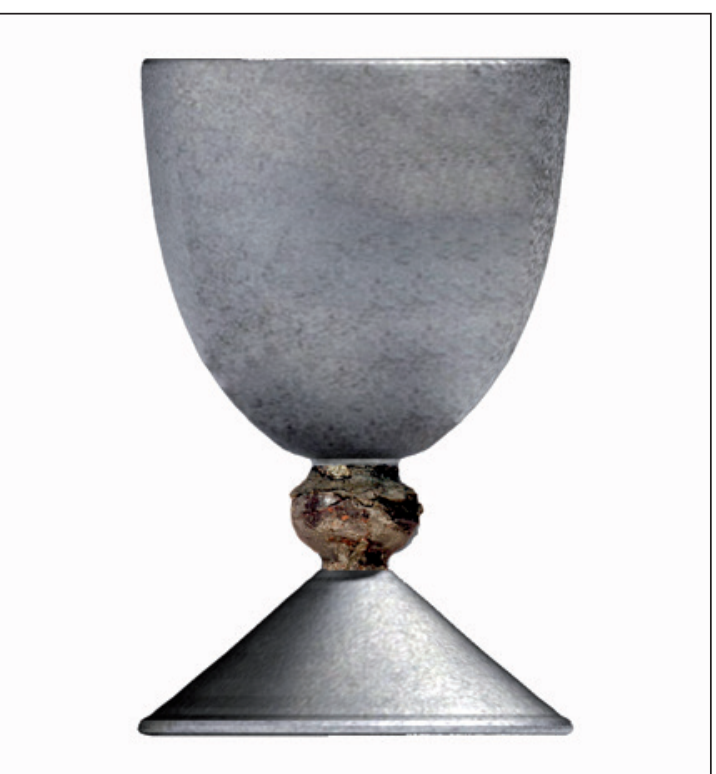

Figura 15. Propuesta de reconstrucción del cáliz de Ifach. Dibujo: Pilar Mas Hurtuna Archivo Gráfico MARQ.

Por el tamaño del nudo y el desarrollo de los paralelos, creemos que el cáliz no tendría una altura inferior a los $12 \mathrm{cms}$, con un diámetro de copa cercano a los 9-10 cms. Por el análisis de algunos restos vinculados con el nudo encontrado entre las manos del inhumado, el grosor de la copa debería rondar los 0,20-0,25 $\mathrm{cms}$.

\section{La patena de Ifach}

En cuanto a la patena, esta se halla muy fragmentada, pudiéndose analizar algunos fragmentos que alcanzan dimensiones no superiores a los 1,4 X 1,6 centímetros con espesor de 0,28 centímetros y un peso aproximado de 2,15 gramos. Su estado fragmentario ha dificultado su estudio formal, ya que los fragmentos conservados, a pesar de ser numerosos, no han revelado nada más que su forma circulary plana, sin poder determinar su diámetro ni su profundidad. La forma circular y plana se asemeja a muchas de las patenas documentadas junto a los cálices revisados anteriormente, caso de las patenas de los obispos Arnau de Creixell, Guillem de Cabanelles y Sant Bernat Calbó, y donde no se aprecia una forma cóncava en su solero, como ocurre, por ejemplo, en el caso de la patena de Sant Salvador de Vedella. En cuanto a sus dimensiones, es absolutamente imposible establecer una reconstrucción física de la pieza, aunque creemos que, por comparativa con los paralelos documentados, no debe de superar los $12-13 \mathrm{cms}$ de diámetro máximo.

En la estructura de muchos de los fragmentos se aprecian con claridad las huellas de la corrosión y también restos de la tierra que la cubría en el interior de la tumba. Su estado de conservación, tan degradado, pensamos que está relacionado muy directamente con la cantidad de estaño (Sn) presente en la aleación. Cuanto más estaño presenta, más se degrada. Además de los factores ambientales que inciden en la corrosión, debemos hacer mención al proceso de desintegración que suele denominarse como la peste del estaño o tin pest (GRACIA I MONT, 1984-85: 315; ZENG, MCDONALD, SWEATMAN, NOGITA, 2014: 135139), por el que se produce una conversión espontánea del $\beta$-Sn a a-Sn al bajar la temperatura por debajo de los 13 grados Celsius. Este proceso es el único conocido de una transformación de fases de estado sólido en el que un material metálico cambia y se convierte en un sólido semiconductor no-metálico como consecuencia del aumento del volumen producido en él y la poca ductilidad del $\alpha$-Sn se producen ampollas y el cuarteamiento del Sn produciéndose su completa destrucción. Muy probablemente el porcentaje significativo de plomo $(\mathrm{Pb})$ de la aleación ha contribuido a preservar parte de la patena, aunque en pésimas condiciones.

\section{Composición de las piezas}

En cuanto a la composición, como se muestran en las dos tablas de materiales adjuntas (Figuras 16 y 17), tanto el cáliz como la patena parecen estar fabricados en peltre, una aleación cuaternaria formada habitualmente por plomo (Pb), en su mayor parte, apareciendo también el zinc (Zn) y el estaño (Sn). Sin embargo, nuestro cáliz de Ifach está compuesto básicamente por una aleación de plomo (Pb) y estaño 


\begin{tabular}{|c|c|c|c|c|c|}
\hline Análisis & $\mathbf{P b}$ & Sn & $\mathrm{Cu}$ & $\mathrm{Zn}$ & Zonas analizadas \\
\hline 1 & 100,00 & $\begin{array}{l}--- \\
--1\end{array}$ & --- & $\overline{-\cdots}$ & Zona cuadrilobuladadel pomo \\
\hline 2 & 42,78 & 54,63 & 2,12 & 0,47 & $\begin{array}{l}\text { Capa situada por encima del pomo } \\
\text { cuadrilobulado }\end{array}$ \\
\hline 3 & 34,29 & 60,68 & 3,82 & 1,20 & Zona distal informe congrietas \\
\hline 4 & 23,36 & 75,57 & 0,80 & 0,27 & Zona distal informe congrietas \\
\hline 5 & 100,00 & --- & --- & --- & $\begin{array}{c}\text { Capa encontactoconel pomo } \\
\text { cuadrilobulado }\end{array}$ \\
\hline 6 & 100,00 & --- & --- & --- & $\begin{array}{c}\text { Capa encontactoconel pomo } \\
\text { cuadrilobulado }\end{array}$ \\
\hline 7 & 21,31 & 77,58 & 1,11 & --- & $\begin{array}{c}\text { Capa situada por encima de la capa } \\
\text { encontactoconel pomo } \\
\text { cuadrilobulado }\end{array}$ \\
\hline 8 & 98,20 & 1,54 & 0,26 & - & $\begin{array}{l}\text { Mancha oscura situada enel borde de } \\
\text { lalalámina situada por encima de la } \\
\text { capa encontactoconel pomo } \\
\text { cuadrilobulado }\end{array}$ \\
\hline 9 & 71,94 & 27,54 & 0,52 & --- & $\begin{array}{c}\text { Capa externa, similar a no } 11 . \\
\text { Presenta grietas }\end{array}$ \\
\hline 10 & 100,00 & --- & --- & ---- & $\begin{array}{l}\text { Capa que recubreal pomo } \\
\text { cuadrilobulado }\end{array}$ \\
\hline 11 & 60,03 & 38,91 & 1,06 & -- & $\begin{array}{c}\text { Capa más externa, recubre a } \\
\text { laanalizadaenel no } 10\end{array}$ \\
\hline 12 & 100,00 & --- & --- & --- & Cuerpodel pomo cuadrilobulado \\
\hline 13 & 38,79 & 59,75 & 1,47 & --- & Parte distal fragmentada \\
\hline
\end{tabular}

Figura 16. Resultados de los análisis mediante microfluorescencia de rayos $x(\mu F R X)$ del probable fragmento del grial. Fuente: Instituto de Materiales (IUMA) del Departamento de Química Inorgánica de la Universidad de Alicante.

\begin{tabular}{cccc}
\hline Elemento & Frag. Patena & Óxidos & Frag. Patena \\
\hline $\mathbf{C a}$ & 10,91 & $\mathbf{C a O}$ & 15,29 \\
$\mathbf{O}$ & 21,81 & --- & -- \\
$\mathbf{S i}$ & 0,55 & $\mathbf{S i O}_{\mathbf{2}}$ & 1,17 \\
$\mathbf{A l}$ & 0,31 & $\mathbf{A l}_{\mathbf{2}} \mathbf{O}_{\mathbf{3}}$ & 0,58 \\
$\mathbf{F e}$ & 1,38 & $\mathbf{F e}_{\mathbf{2}} \mathbf{O}_{\mathbf{3}}$ & 1,96 \\
$\mathbf{M g}$ & 0,33 & $\mathbf{M g O}$ & 0,54 \\
$\mathbf{K}$ & 0,08 & $\mathbf{K} \mathbf{0}$ & 0,09 \\
$\mathbf{P b}$ & 9,90 & $\mathbf{P b O}$ & 10,66 \\
$\mathbf{S n}$ & 54,41 & $\mathbf{S n O}_{\mathbf{2}}$ & 69,12 \\
$\mathbf{S}$ & 0,19 & $\mathbf{S O}_{\mathbf{3}}$ & 0,46 \\
$\mathbf{C l}$ & 0,13 & $\mathbf{C l}$ & 0,13 \\
\hline
\end{tabular}

Figura 17. Resultados de los análisis mediante FRX del fragmento de la patena de Ifach dados en porcentaje en peso normalizados de los elementos y sus óxidos. Fuente: Instituto de Materiales (IUMA) del Departamento de Química Inorgánica de la Universidad de Alicante.

(Sn), donde el núcleo de la parte central cuadrilobulada que serviría de unión entre el pie del cáliz y la zona de la copa propiamente dicha. En donde se depositaría el líquido muestra una composición cercana al
100\% de plomo (Pb). La mayoría del peso de

la muestra se atribuiría a esta zona.

Sin embargo, en la zona de rotura que se muestra como la más degradada de la pieza, 
es donde se incorpora el zinc (Zn) como elemento residual de la aleación. En esta zona el estaño (Sn) predomina con valores que van desde el 54,63\% al 75,57\%, el plomo (Pb) tiene porcentajes entre el $23,36 \%$ y el $42,78 \%$ y como elementos residuales aparecen el cobre (Cu) con valores entre el $0,80 \%$ y el $3,82 \%$ y el zinc (Zn) con valores entre el 0,27\% y el 1,20\%. Su estado de conservación, tan degradado, pensamos que está relacionado muy directamente con la cantidad de estaño (Sn) presente en la aleación, ya que, como hemos señalado anteriormente, cuanto más estaño presenta, más degradación muestra.

Recordemos que el peltre es una aleación sumamente dúctil y maleable que ofrece un aspecto exterior muy similar a la plata, aunque funde a 1700-2300 grados, una temperatura muy baja en comparación con la plata que funde a 9600 grados. La capacidad del peltre de ofrecer pátinas de tono argentífero con muy poco metal, permite fabricar piezas que, a primera vista, parecen hechas de plata, lo que abarata los costes de fabricación pensando en una venta posterior, siendo piezas de precio muy asequible en el mercado de la época. Además, la maleabilidad del peltre le permite ser utilizado para dar forma a innumerables adornos que acompañan a otras piezas, así como para formar piezas propias. En algunas ocasiones, se estima utilizarlo para recubrir piezas de plomo, como se ha podido comprobar en un pie de cáliz encontrado en la tumba de un monje del Monasterio de San Pelayo en Quintana de Valdelucio (Villadiego, Burgos) perteneciente en la segunda mitad del siglo XIV, la parte conservada del pie del cáliz es de plomo recubierto por una ligera capa de azófar (OSABA, RUIZ DE ERENCHUN, 1964: 77).

Por otra parte, en los análisis de $\mu$-FRX realizados por el Instituto de Materiales de la Universidad de Alicante también se ha podido confirmar la existencia de trazas de algún tipo de decoración, que no es observable a simple vista debido al estado de deterioro de la pieza. Las trazas decorativas nos permiten plantear que este motivo podría relacionarse con una imagen simbólica del denominado como Te- tramorfo, la presencia del cual es habitual en muchos cálices de mejor factura. El Tetramorfo es un conjunto de cuatro seres que se disponen alrededor del trono de Dios y que se asimilan a los cuatro evangelistas su función era alabar, glorificar y dar gracias a Dios. El tetramorfo solo aparece rodeando a Dios, por lo cual su posición en el cáliz estaría relacionando estas funciones con el significado de la Eucaristía que se desarrollaría en el interior de la copa del cáliz. También y siempre como hipótesis, los cuatro vástagos sobre los cuales se apoyaría la copa podrían simular hojas vegetales o pétalos, con el que su apariencia sería el de una flor desde la cual nace la copa que contendrá la eucaristía. Esta copa, de acuerdo con la tipología genérica de cálices góticos más reciente (SANJOSÉ-LLONGUERAS, 2015), tendría una forma cónica y lisa.

\section{EL CÁLIZ Y LA PATENA DE IFACH EN EL CONTEXTO PENINSULAR}

La identificación de este tipo de piezas como las halladas en la pobla de Ifach la podemos circunscribir de forma mayoritaria al espacio geográfico situado en el área catalana y, en concreto, en el área norte de este territorio (Figura 18). Aun así, existen algunos ejemplares que se localizan en el área centropeninsular como es el caso del ya citado cáliz de Quintana de Valdelucio (Villadiego, Burgos), pero, sin ninguna duda, la concentración más intensa de cálices y patenas de peltre se encuentra en Cataluña.

Existe una amplia bibliografía que, a lo largo del siglo XX y buena parte del siglo XXI, ha analizado y estudiado este tipo de piezas dentro de lo que podemos definir como orfebrería medieval catalana. Ciertamente, los primeros trabajos se los debemos a toda una referencia de la historia y arqueología catalana como es Josep Gudiol i Cunill, quien en el año 1902 dejó su obra Nociones de arqueología sagrada catalana, en un intento de poner orden y algo de contexto en el amplio número de exposiciones de artesanía que durante el tercer cuarto del siglo XIX se habían comenzado a realizar 


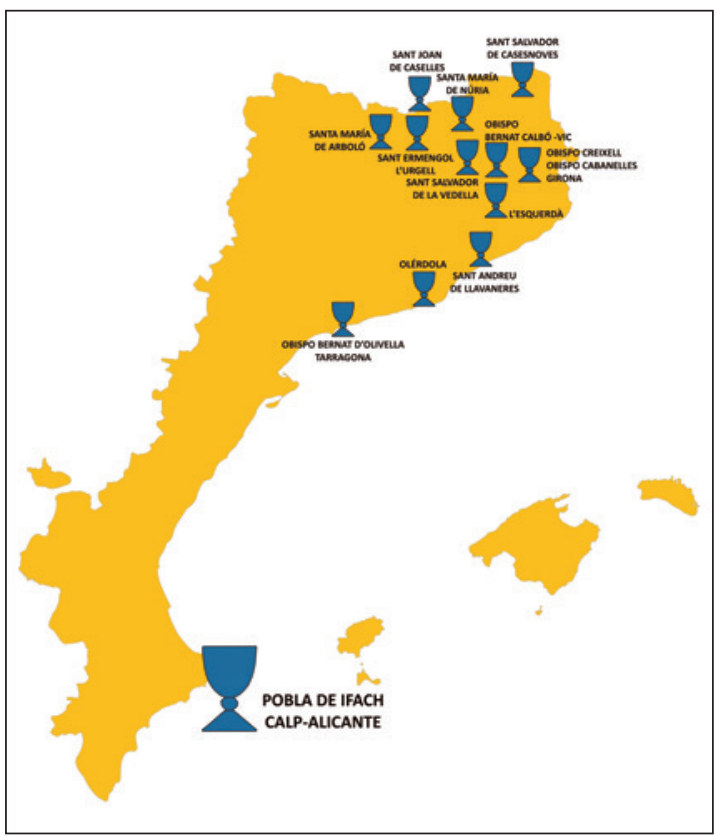

Figura 18. Mapa de dispersión de los cálices litúrgicos documentados en el territorio catalán.

en ciudades de importante tradición medieval como Barcelona o Vic, apoyada por la iniciativa de coleccionistas privados con la necesaria contribución de los obispados y algunas instituciones de corte religioso. La obra de Gudiol se antoja fundamental como primera aproximación a este tipo de piezas (Figura 19), ya que presenta por vez primera un material que nunca había visto la luz y cuya documentación histórica comenzaba a situarlas en el contexto histórico correcto.

En la misma línea, aunque con una vocación más peninsular y menos catalana, se encuentran las Nociones de Arqueología Cristiana para uso de los seminarios conciliarios de José de Manjarrés (1867), un trabajo en el que no se aprecian grandes novedades con la obra de Gudiol, pero que apoya y refuerza la existencia de un gran conjunto de piezas que comenzaban a mostrarse en el panorama científico.

Junto a ambas obras debemos incluir los catálogos editados por el Museu Episcopal de Vic, un museo abierto en el año 1893 sobre una colección reunida en la Exposición Arqueológico-Artística en el año 1868 en el claustro del convento de Sant Domènec, organizada por Jaume Collell, junto al mossén Cinto Verdaguer y los miembros del Círculo Literario de Vic (ORDEIG I MATA, 1991: 325-356), quienes impulsaron definitivamente la necesidad de coleccionar y musealizar el arte medieval, al igual que ya había ocurrido, por ejemplo, en la ciudad de Barcelona con la Exposición Retrospectiva del año 1867 (TRULLÉN I THOMÀS, 2003: 270) y en los catálogos del Museu Diocesà de Barcelona en 1916, la sección de arte románico del Museu de la Ciutadella, origen del actual Museu Nacional d'Art de Catalunya (MNAC) en el año 1926 o el de la Colección Plandiura en el año 1932. En estos dos últimos casos, fue Joaquim Folch i Torres (1926), quien publicó el catálogo completo de ambas colecciones que sirvieron como base para su Monumenta Cataloniae publicada en el año 1956.

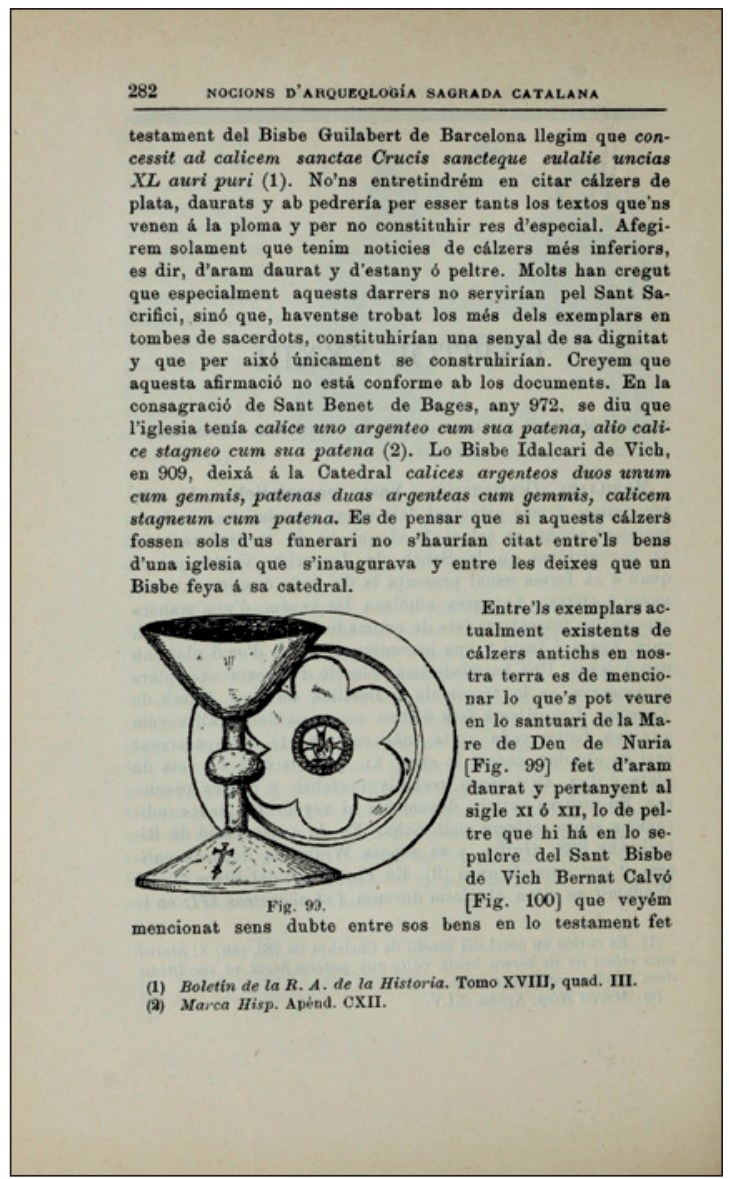

Figura 19. Página del estudio de los cálices litúrgicos catalanes del Nociones de arqueología sagrada catalana de Josep Gudiol i Cunill del año 1902. 
Después de la guerra civil, el panorama científico relativo al estudio de este tipo de piezas se centra en la edición de nuevos catálogos de exposiciones que matizan y mejoran lo ya aportado por Josep Gudiol en décadas anteriores. En este sentido, importante fue la celebración de la Exposición de Arte Románico de Barcelona del año 1961 por parte del Consejo de Europa, una muestra que contribuyó a expandir más allá de nuestras fronteras el conocimiento del arte románico y de su registro material. Además, este resurgir coincide en el tiempo con una oleada de publicaciones realizadas sobre el arte románico catalán en el que destaca la obra Pinturas románicas de W.S. Cook y Juan Ainaud de Lasarte (1957), editado por la UNESCO en diferentes idiomas durante los años 1962 y 1963 - la obra Trèsors d'orfeverie des églises du Roussillon et du Languedoc méditerranéen de Marcel Durliat, Jean Claparède y Jean Thuile publicada en el año 1954.

Pero el momento de nuestro conjunto de piezas deberá esperar hasta la década de los 80 del siglo XX, cuando, con la llegada de la democracia, el reinstaurado estado autonómico inicia un proceso de recuperación y reconexión del patrimonio histórico con la sociedad catalana con el objetivo de resignificar monumentos y materiales que el paso de la época franquista había ocultado en un largo proceso de replegament catalán. En este contexto asistimos a la eclosión del románico catalán con publicaciones especializadas en el arte suntuario poniendo de relieve el papel de la orfebrería catalana. Figura fundamental de este momento será Elisènda Gràcia i Mont y sus estudios sobre las piezas de peltre procedentes de ajuares funerarios de clérigos y obispos publicados en los números 5-6 y 7-8 de la revista Acta Historica et Archaeologica Mediaevalia (1984-1985: 313-354; 1986: 453458). Aunque naciendo sin un afán específico de ser una búsqueda exhaustiva de todas las piezas de peltre existentes en territorio catalán, el trabajo de Gràcia i Mont permite mostrar una primera reunión de piezas centradas exclusivamente en el peltre como material de fabricación, eliminando otros tipos de mate- riales como oro, plata que son más característicos de lo que conocemos con el término de orfebrería.

Eso sí, su búsqueda le permitió, no solo mostrar un conjunto sólido de ejemplares (Figura 20) procedentes de colecciones museísti-

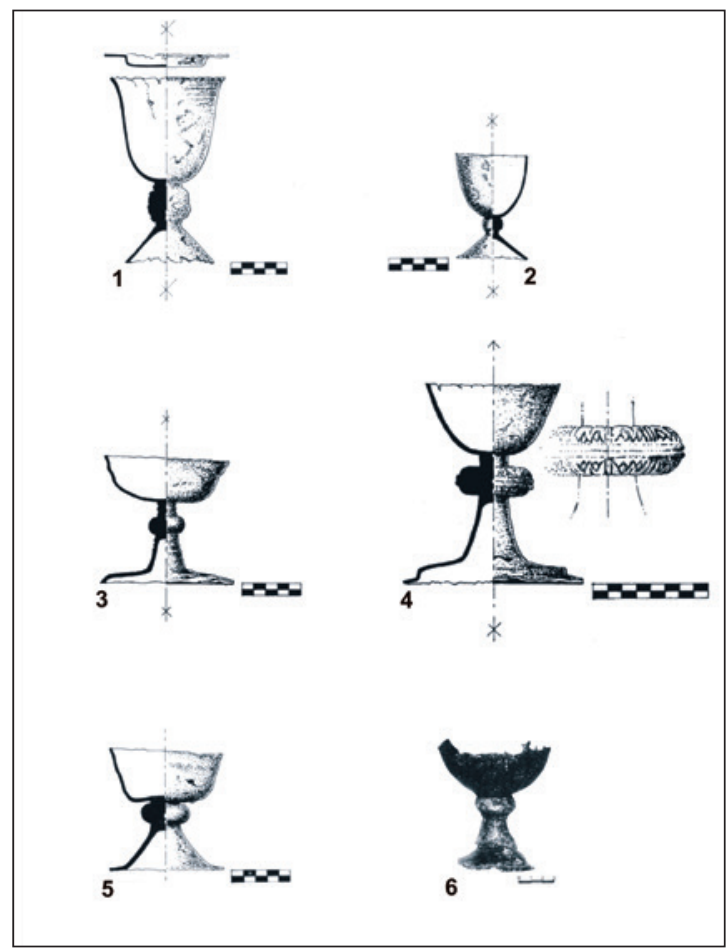

Figura 20. Cálices catalanes segun el estudio de Elisenda Gràcia Mont: 1. Sant Salvador de la VedeIla; 2. Sant Ermengol; 3. Sant Bernat Calbó; 4. Sant Andreu de Llavaneres; 5. l'Arboló; 6. Grial del Obispo Cabanelles.

cas -9 cálices y 8 patenas-, sino también mostrar alguna de las recientes novedades que por entonces no procedían de los fondos de los museos episcopales sino de las prospecciones y excavaciones arqueológicas realizadas en esos mismos años, como le sucede a los fragmentos de los tres cálices del yacimiento de L'Esquerdà (Figura 21), localizados por L'Unió Excursionista de Roda y depositados en el Museo Municipal de Roda de Ter, hallados en un poblado fechado en los siglos XII-XIII cuyo abandono se produce de forma definitiva en el año 1314 (OLLICH I CASTANYER, 2003: 145165). 


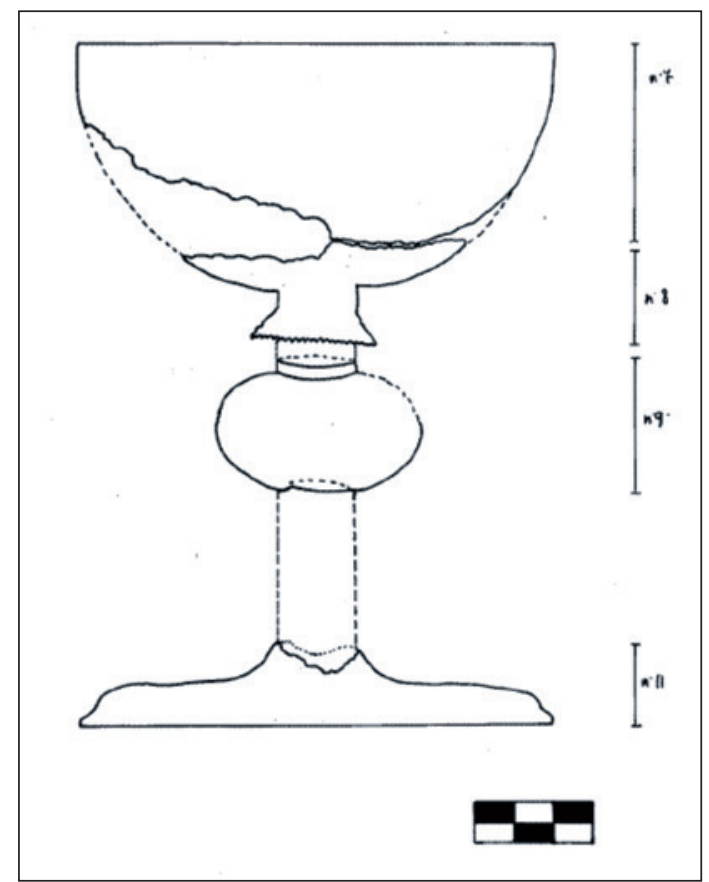

Figura 21. Reconstrucción de uno de los cálices hallados en el yacimiento medieval de l'Esquerda, según Elisenda Gràcia i Mont, 1984-1985: 349.

El catálogo de Elisènda Gràcia i Mont, recoge el caso del cáliz de la Iglesia de Sant Salvador de la Vedella -referencia MDCS 579, 580-, expuesto en el Museo Diocesano y Comarcal de Solsona perteneciendo al Monasterio de Sant Salvador de la Vedella en Cercs (Berguedà) y datado en los siglos XII-XIII (GUDIOL I CUNILL, 1931-1933: I, 451; SERRA I VILARÓ, 1960: 169-170; VIGUÉ I VINYAS, BASTARDES I PORCEL, 1978: 280; RIU I RIU, 1982: 45; GRÀCIA I MONT, 1984-1985: 319-323 y 335; 1986: 93-94; VARIOS AUTORES, 1990: 154; DURAN-PORTA, 2015: II, 10; SANJOSÉ LLONGUERAS, 2015: 580-584); y el conocido como Cáliz de San Ermengol, con la referencia MDU 904, existente en el Museo Diocesano de Urgell, datado en el siglo XII y perteneciente a la Catedral de Santa María de la Seu d'Urgell (Alt Urgell) (VIVES I MIR, 1980: 496; GRÀCIA I MONT, 1984-1985: 318-319; PEIRIS I PUJOLAR, 1988: 261-262; ADELL I GISBERT et al., 2000: 135; DURAN-PORTA, 2015: II, 11; SANJOSÉ LLONGUERAS, 2015: 574-577).
También aparecen los casos del llamado cáliz y patena funeraria del Obispo Arnau de Creixell de Girona -con referencia TCG 91b-, datadas alrededor del año 1214 y pertenecientes al Tesoro de la Catedral de Girona, exhibidas actualmente en el Museo Nacional de Arte de Cataluña (MNAC) (CASANOVAS I ROMEU, 1988: 152-153; GRÀCIA I MONT, 1986: 454-458; DURAN-PORTA, 2015: II, 13; SANJOSÉ LLONGUERAS, 2015: 592-596); el llamado Cáliz de Arboló -con referencia MDU- datado en los inicios del siglo XII y perteneciendo en la Iglesia de Santa María de Arboló (Pallars-Sobirà), que se encuentra expuesto en el Museo Diocesano de La Seu d'Urgell (GRÀCIA I MONT, 1984-1985: 321-323; PEIRIS I PUJOLAR, VIGUÉ I VINYES, 1988: 262; DURAN-PORTA, 2015: ॥, 12; SANJOSÉ LLONGUERAS, 2015: 586-590); o el caso más tardío del Cáliz de Núria d'Urgell, con referencia MDU 27-28, datado en la primera mitad del siglo XIII, procedente del Santuario de la Virgen María de Núria en el Ripollés y expuesto en el Museo Diocesano de La Seu d'Urgell (GUDIOL I CUNILL, 1902: 282; SOLÀ I MORETA, 1952: 180; CASTELLS SERRA, 1975: 259; GIRONA, 1985: 147-148; PEIRIS I PUJOLAR, 1988a: 262-263; AINAUD I ESCUDERO, 1989: 220; 1992: 173; ESPAÑOL BERTRÁN, YARZA LUACES, 2007: 168; DURÁN-PORTA, 2015: II, 9; SANJOSÉ LLONGUERAS, 2015: 612-615).

Del mismo tipo encontramos más piezas, como el cáliz y patena del Arzobispo Bernat de Olivella (Figura 22) -con referencia MDT 3332-3333-, encontrado en su sepulcro de la Iglesia de Santa Tecla la Vieja, junto al conjunto de la Catedral de Tarragona y datado antes de 1287 (SERRA I VILARÓ, 1960: 168; GRÀCIA I MONT, 1984-1985: 325-329; 1986: 94-95; MARTÍNEZ SUBÍAS, 1992: 82; 2013: 523; LÓPEZ VILAR, 1999: 156; RAMON I VINYES, 1989: 224-225; DURAN-PORTA, 2015: ॥, 16; SANJOSÉ LLONGUERAS, 2015: 612-615); el cáliz de Sant Salvador de Casesnoves -con referencia CL1 1989-, que se encuentra en el Museé de Cluny-Museé National du Moyen Age en París, datado en la segunda mitad del siglo XII (DALMAU, 2010: 116; PERRIN, VASCO-ROCCA, 1999: 210; PONSICH, 1993: 98; 1993a: 243; DURAN-PORTA, 2015: II, 8). 


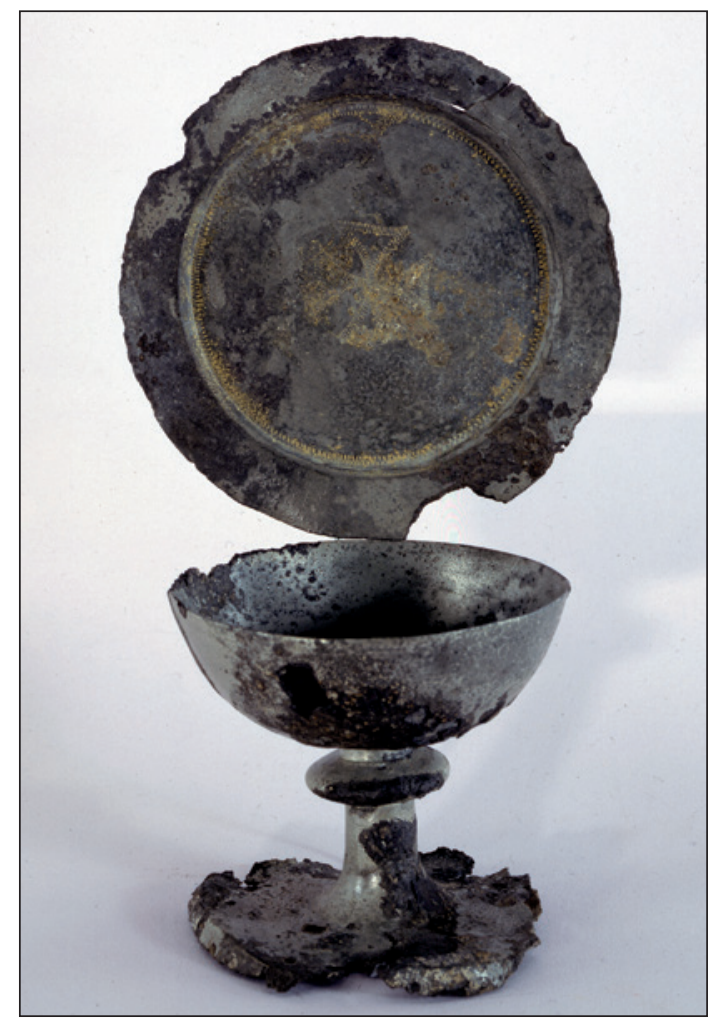

Figura 22. Cáliz y patena del Obispo Bernat d'Olivella. Segunda mitad del siglo XIII. Museo Catedralicio de Tarragona.

También conviene incluir en estas referencias al cáliz y patena del Obispo Cabanelles (CALZADA I OLIVERAS, 1979: 62; CASANOVAS I ROMEU, 1988: 154; GRÀCIA I MONT, 455-458; DURAN-PORTA, 2015: I, 14; SANJOSÉ LLONGUERAS, 2015: 598-602), -con referencia 91b-, del Tesoro de la Catedral de Girona datado en la primera mitad del siglo XIII; el cáliz y patena de Santo Bernat Calbó, -con referencia MEV 10614-10615- del Museo Episcopal de Vic, datado en la primera mitad del siglo XIII y perteneciendo a la Catedral de Vic (GUDIOL I CUNILL, 1902: 282-283; 1909: 964-977; FORT । COGULL, 1979: 258; GROS I PUJOL, ORDEIG I MATA, 1980: 139; GRÀCIA I MONT, 1984-1985: 335-336; CASANOVAS I ROMEU, GRÀCIA I MONT, 1986: 229-230; 1986: 722-724; DURAN-PORTA, 2015: II, 15; SANJOSÉ LLONGUERAS, 2015: 604606) o el cáliz y patena de Sant Andreu de Llavaneres -con referencia MEV 9710- del Museo Episcopal de Vic, datado en el siglo XIII y perteneciendo en la Iglesia de Sant Andreu de Llava- neres (Maresme) )(FITA I COLOMER, 1897: 239240; GUDIOL I CUNILL, 1902: 283; 1920: fig. 11; 1931-1933: I, 271; SOLÀ I MORETA, 1968: 26-27; GRÀCIA I MONT, 1984-1985: 325-326, 335-337; CASANOVAS I ROMEU, 1986: 231; CLARIANA I ROIG, 1991: 17; 1992: 496; DURAN-PORTA, 2015: II, 17; SANJOSÉ LLONGUERAS, 2015: 608-610).

La misma Elisènda Gràcia i Mont es también partícipe de otra de las obras de referencia de estos años como será la enciclopédica Catalunya Romànica, que sirvió para dar cobertura definitiva a todas las piezas existentes en los museos catalanes. Aparte de estas obras, surgen numerosas exposiciones sobre arte y arqueología catalanas que, de forma recurrente, acaban aportando nuevas fichas de catalogación y detalles sobre el conjunto de piezas de peltre. Son los casos de Thesaurus, l'art als Bisbats de Catalunya 1000/1800 (Palau Macaya, 1986), Millenium, història i art de l'Església catalana (Pia Almoina, 1989), Catalunya Medieval (1992), Catalunya a l'época carolingia. Art i cultura abans del romànic (MNAC, 1999), Catalunya i la Mediterrània (MNAC, 2008) realizadas en Barcelona o las muestras Pallium (Tarragona, 1992), Pulchra (Lleida, 1993) y Fidei Speculum, Art litúrgic de la Diòcesi de Tortosa (2000) relizadas en otras ciudades con importantes museos catredalicios como Tarragona, Lleida o Tortosa.

En este sentido, debemos incluir en estas décadas el hallazgo de otro importante ejemplar y que no recoge el catálogo de Elisènda Gràcia i Mont, como es el cáliz de Sant Joan de Caselles, una pieza del ajuar de una tumba de un posible presbítero en un excelente estado procedente de las excavaciones realizadas en el año 1988 en la necrópolis medieval de este singular yacimiento andorrano de época medieval (GUILLAMET, LLOVERA, 1989).

Con la llegada del siglo XXI, se detecta un incremento en el interés sobre este tipo de piezas, aumentado con el descubrimiento del cáliz y patena de Olérdola, uno de los enclaves arqueológicos con más solera científica del área catalana (MOLIST I CAPELLA, et al., 2011: 147-159). El hallazgo se produjo durante las ex- 
cavaciones realizadas en los años 2005-2007, en concreto en la denominada Tumba 30 -individuo 18-, donde las piezas aparecieron en el lado derecho del cráneo con una datación por radiocarbono situada entre mediados del siglo X y primer cuarto del siglo XI (946-1037) (MOLIST I CAPELLA; BOSCH I CASADEVALL, 2012: 483).

Junto al nuevo hallazgo, las novedades en la investigación se dirigen al ámbito académico, dejando a un lado los catálogos de exposición. Nos referimos a la lectura de dos tesis doctorales presentadas en el año 2015, que abordan el tema y manejan prácticamente el mismo registro material como base de su investigación. La primera de las tesis es la obra L'orfebreria románica a Catalunya (950-1250), elaborada por Joan Duran-Porta (2015) y dirigida por la Dra. Anna Orriols i Alsina desde la Universidad Autónoma de Barcelona (UAB). La segunda de las tesis es la defendida por Lourdes de Sanjosé Llongueras (2015) con el título L'obra de Llemotges i d'altres orígens: L'obra de metall als segles XII-XIII a Catalunya, dirigida por el Dr. Antoni José i Pitarch, Catedrático de Arte de la Universidad de Barcelona. Ambos estudios son encomiables esfuerzos por profundizar en el estudio de la metalistería medieval en el área catalana que, en el pasado, como hemos visto, había ofrecido buenos resultados y estudios tanto en cantidad como en calidad.

Partiendo de un importante esfuerzo de regesta documental, ambas obras cruzan en ocasiones las líneas de los límites de sus horquillas cronológicas de referencia. En concreto, la obra de Duran-Porta parece centrarse exclusivamente en lo que denomina orfebrería catalana altomedieval, aunque cruce en ocasiones un metafórico Rubicón para incluir algunas piezas de relevancia como el cáliz de Nùria, obra considerada de pleno siglo XIII. Por otra parte, el trabajo de Sanjosé Llongueras parece centrarse en las obras de plena cronológica medieval, aunque utiliza piezas como el cáliz de Sant Ermengol o el cáliz y patena de Olérdola de una clara cronología altomedieval (2015: 570-571).

En cuanto al catálogo de piezas estudiadas, ambos también muestran carencias y novedades por igual si utilizamos como piedra comparativa los trabajos de Elisenda Gràcia i Mont. En este sentido, la obra de Duran-Porta recoge hasta una decena de cálices y 7 patenas. La principal aportación se centra en presentar el cáliz de la iglesia de Sant Salvador de Casesnoves ${ }^{10}$, fechado en la segunda mitad del siglo XII, que se encuentra depositado en el Museé de Cluny (Francia) y que no es recogido en la obra de Elisènda Gràcia i Mont (2015: II, 8) ni en el posterior trabajo de Sanjosé Llongueras. Sin embargo, no hace mención a los principales hallazgos procedentes de excavaciones arqueológicas como son los casos del cáliz y patena de Olérdola, el cáliz de Sant Joan de Caselles y creemos que, debido a su estado fragmentario, el cáliz y patenas del yacimiento de L'Esquerdà. Algo similar le ocurre a la tesis de Lourdes de Sanjosé Llongueras, que también recoge 10 cálices y 8 patenas, incluyendo en el catálogo el cáliz y patena de Olérdola, pero obviando los ejemplares de Casesnoves, Sant Joan de Caselles y L'Esquerda. La ausencia del cáliz de Casesnoves puede justificarse al tratarse de una pieza que se encuentra en un museo francés, fuera del ámbito territorial catalán; mientras que las ausencias de Olérdola y L'Esquerdà pueden explicarse por las mismas razones que en el caso de la tesis de Joan Duran-Porta y es el estado fragmentario de las piezas documentadas.

Aparte de los ejemplares catalanes ya mostrados en el estudio de Elisenda Gràcia i Mont y en posteriores, este tipo de cálices es muy frecuente encontrarlos desde fecha muy temprana distribuidos por el Mediterráneo, área centroeuropea y Reino Unido. Entre las piezas más destacadas cuya morfología se acercaría a nuestro ejemplar de Ifach, pode-

10. En cambio, ya había sido citado por Marciel Darcel a finales del siglo XIX (1890) y es recogido en diversos trabajos publicados en la última década del siglo XX (Perrin, Vasco-Rocca, 1999: 210; Ponsich, 1993: 98; 1993a: 243) e incluso años antes de la edición de las dos tesis doctorales (Dalmau, 2010: 116). 


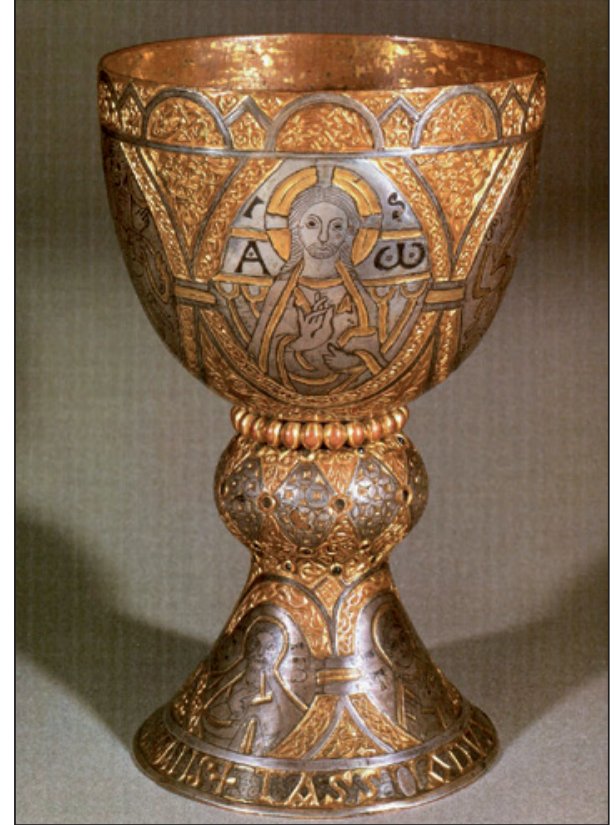

Figura 23. Cáliz de Tassilo (Schatzkammer, Austria). Segunda mitad del siglo VIII.

mos citar el cáliz de Tassilo de Bavaria en Alemania fechado entre el 768-788 (SANJOSÉ-LLONGUERAS, 2015: 77) (Figura 23); el cáliz de Grimfidus (ROSS, 2005: 131-132) o el cáliz de Sant Ludger de la iglesia de Werden (Alemania) (SANJOSÉ-LLONGUERAS, 2015: 69).

Precisamente, y sin ánimo de ser exhaustivos, es interesante señalar que la representación de estos cálices suele encontrarse también en la ilustración de manuscritos como, entre otros, el del Beato de Girona (WILLIAMS, 1994: n 309)(Figura 24); la Biblia de Rodas fechada entre los años 1010-101511; o los Evangelarios de Porpra, (GULLATH, 2012: 66-67) y del Obispo Bernard Hildesheim (SANJOSÉ LLONGUERAS, 2015: 262), datados en el primer tercio del siglo IX. También es habitual encontrarlo en armoriales o libros de heráldica medieval como el Códice Manesse o el Armorial de Heildelberg, datado entre los años 1300-1340 (Figura 25).

Y, por supuesto, es muy habitual verlo en la pintura románica y gótica del área catalana,

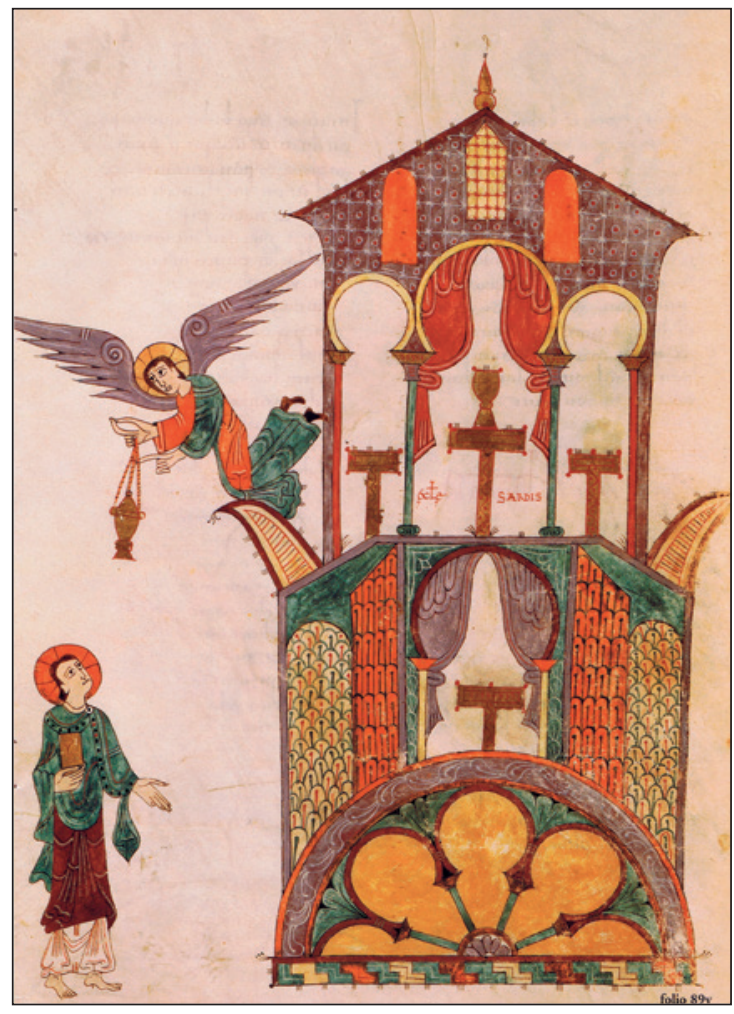

Figura 24. Página del Beato de Girona donde se aprecia la presencia de un cáliz como el de Ifach. Folio 89v. Museo de la catedral de Girona.

donde encontramos ejemplares muy similares al documentado en Ifach en los frescos de las paredes de la Iglesia de Sant Pere de Sorpe (Àneu-Pallars Sobirà), fechados en la mitad del siglo XII; en la iglesia de Santa María de Taüll, pintada por el maestro del Juicio Final (Figura 26); en la iglesia de Esterri de Cardòs de la segunda mitad del siglo XII (CARBONELL I ESTELLER, SUREDA I PONS, 1997: Fig. 16) o en la iglesia de Sant Romà de les Bons d'Encamp, pintado por el maestro de Santa Coloma (SANJOSÉ LLONGUERAS, 2015: 272, Figura 100) o las pinturas del ábside de Sant Esteve d'Andorra la Vella, fechadas en la primera mitad del siglo XIII (PAGÉS I PARETÉS, 2015: 286), todas ellas expuestas actualmente en el Museu Nacional d'Art de Catalunya (MNAC) en Barcelona. También lo podemos encontrar en la Santa Cena de la antigua capilla de la Catedral de la Seu d'Urgell, datada en 1242-1255 y el frontal

11. Escenas del Libro del Apocalipsis, Biblia de Rodas, Bibliothéque Nationale de París, lat 6, IV, fol. 107v. 


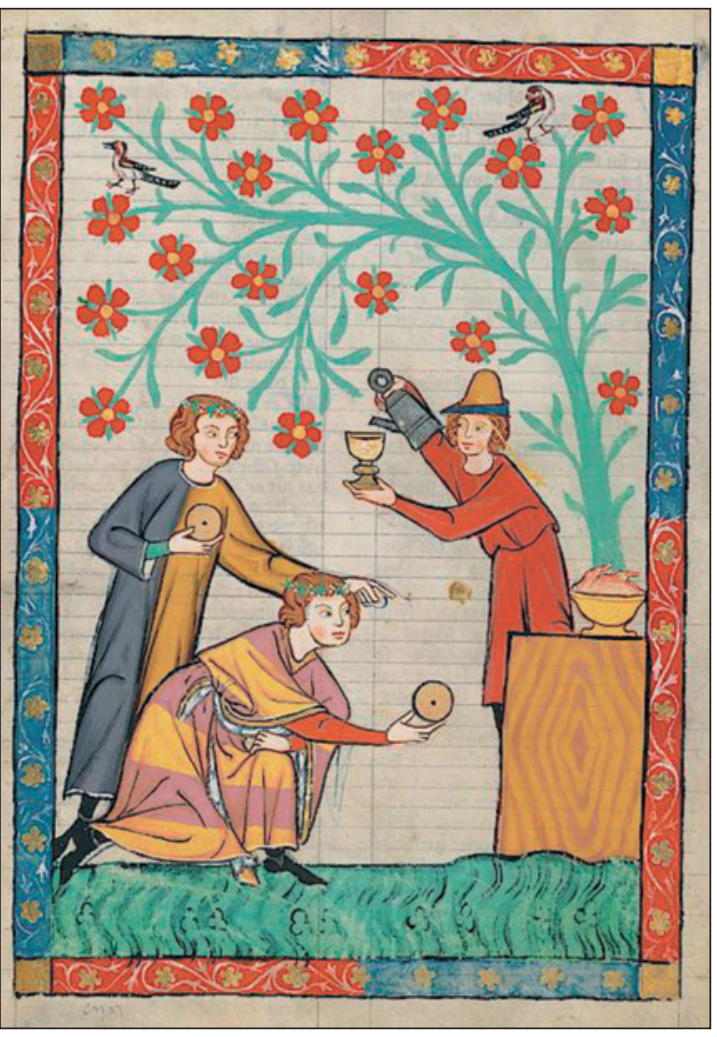

Figura 25. Imagen perteneciente al Codice Manesse o Armorial de Heidelberg donde aparece un cáliz como el de Ifach. Primera mitad del siglo XIV. Biblioteca de la Universidad de Heidelberg.

de San Martín de Chía (Ribagorza, Huesca), los dos expuestos en el Museo Episcopal de Vic (MEV) (Figura 27).

Así mismo, en el fresco del Apostolado de Santo Romano de los Bonos (Encamp, Andorra), datado hacia 1164; en el pórtico de la Canónica San Vicente de Cardona (El Bagés), datado hacia 1200; en los frontales de las mesas de Sant Hilari de Vidrà (SANJOSÉ LLONGUERAS, 2015: 275); en el de la Capilla del Corpus Christi de la iglesia del Monasterio de Santa Maria de Vallbona de les Monges en Urgell, datada entre 13351345; en la de San Miquel de la Iglesia Parroquial de Santo Miquel de Soriguerola (Fontanals de Cerdanya, Baja Cerdaña), datada a finales del siglo XIII y en el frontal de la Iglesia de Santo Miquel de Tamarit de Litera (Huesca), datada en la primera mitad del siglo XIV, todos ellos expuestos también en el Museo Nacional de Arte de Cataluña (MNAC) en Barcelona.

\section{LA CRONOLOGÍA DEL CÁLIZ Y PATENA DE IFACH}

Los datos concretos aportados por la analítica vienen fundamentalmente sostenidos por la cronología de las muestras de los restos óseos del cimiterium suministrada por el Centro Nacional de Aceleradores del Consejo Superior de Investigaciones Científicas (CSIC) con sede en Sevilla. Entre todas las muestras realizadas hasta ahora (17), nos interesa destacar la muestra con firma CNA-2858.1.1., en la que se establece una horquilla cronológica genérica por calibración $2 \sigma$ entre los años 1300-1370, fechas que coinciden casi plenamente con el marco cronológico general de vida del yacimiento.

Por otro lado, la datación relativa -al 51\% de probabilidades-, sitúa la horquilla entre los años 1345-1394, fechas que coinciden plenamente con la fecha post-quem aportada por las excavaciones en el edificio religioso de la pobla, donde un croat de plata de Alfons IV el Benigno documentado sobre el pavimento de

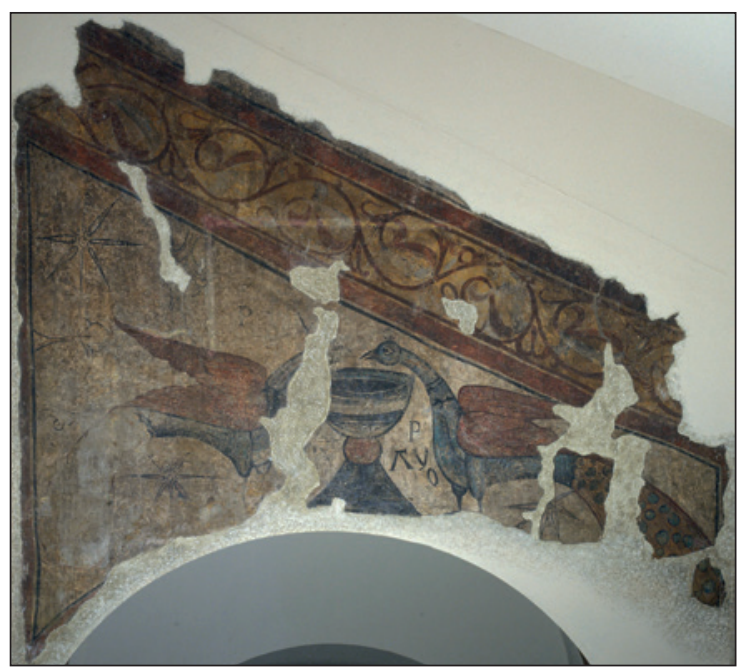

Figura 26. Detalle de un cáliz representado en uno de los murales de la iglesia de Santa María de Taüll. Siglo XII. Museu Nacional d'Art de Catalunya (MNAC). 


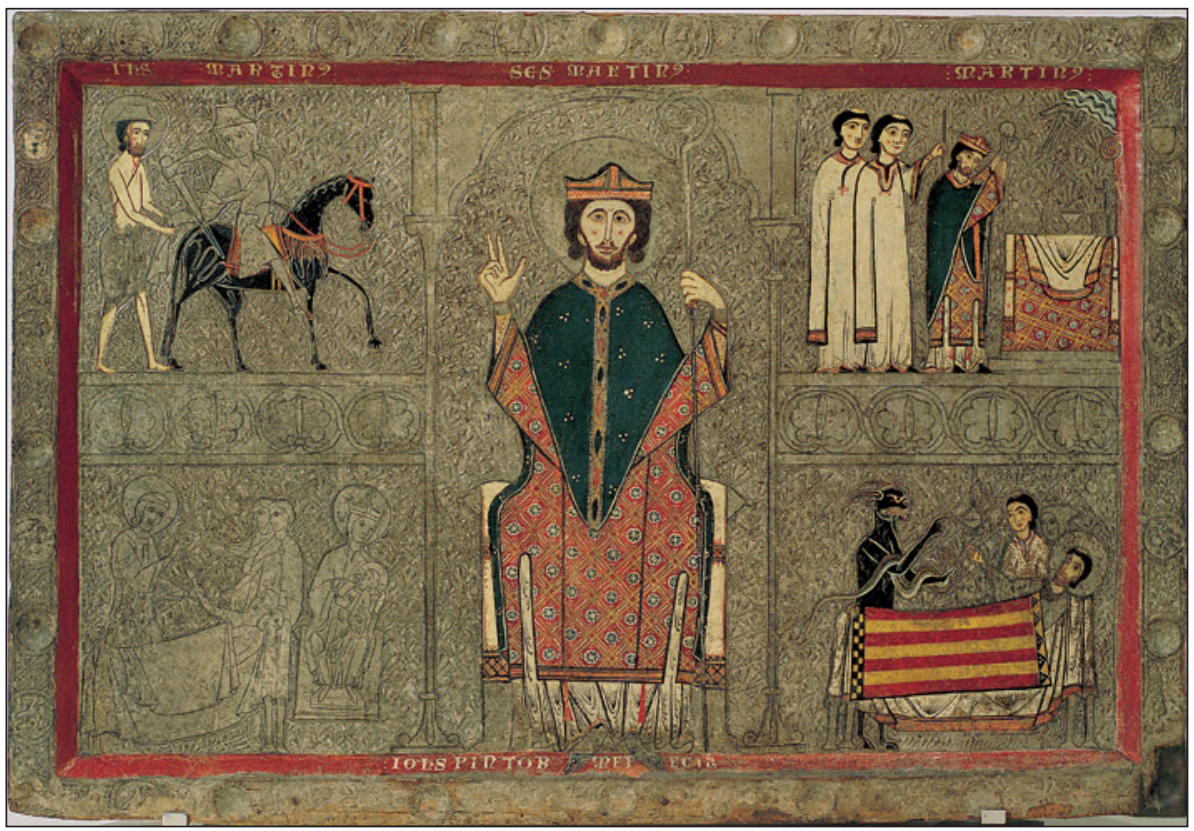

Figura 27. Frontal de San Martín de Chía (Ribargoza, Huesca). Segunda mitad del siglo XIII. Museo Episcopal de Vic (MEV) - Museu Nacional d'Art de Catalunya (MNAC).

la Capilla Sur 2, permite datar las capillas entre los años 1327-1336 (SÁNCHEZ SIGNES: 2018: 278-279, n³2).

Otro detalle cronológico importante nos lo ofrece la secuencia constructiva y estratigráfica de la fosa de la T13, la cual, para que pudiera abrirse era imperativo que la fachada de la iglesia estuviera acabada, dado que la fosa apoya en el extradós del edificio. Este detalle nos indica una fecha post-quem con la construcción de la iglesia que, como hemos indicado en trabajos específicos sobre el templo (MENENDEZ, KISS, PINA, 2018: 117-144), podíamos situar hacia la mitad del siglo XIV, coincidiendo con lo que señala el testamento de Margarita de Lauria y Entenza, quien encarga la finalización de las obras del edificio religioso en $1344^{12}$ como Señora de Ifach.

Por todo lo expuesto, planteamos que la cronología de las piezas debe situarse en la segunda mitad del siglo XIV. Esta datación que podemos considerar algo tardía muestra evidentes diferencias cronológicas con las mostradas por sus referentes morfológicos ubicados en el área catalana y que hemos expuesto en párrafos anteriores, gracias fundamentalmente a los trabajos de Elisenda Gràcia i Mont 1984-1985: 313-354; 1986: 453458), Joan Duran-Porta (2015) y Lourdes de Sanjosé Llongueras (2015). Las fechas aportadas por el estudio de estos paralelos parecen otorgar la datación más moderna al cáliz del Obispo Arnau de Creixell, situándolo en fechas anteriores a 1335 (GRÀCIA I MONT, 1984-1985: 325), fecha en la que no parecen estar de acuerdo tanto Joan Duran-Porta (2015: II, 13) como Lourdes de Sanjosé LLongueras que lo sitúan en una fecha anterior al año 1214 (2015: 592-596). Para ambos estudios, las piezas cronológicamente más modernas serían los cálices del Santuario de la Virgen María de Núria y el de Sant Andreu de Llavaneres con las dataciones más modernas, situadas en la primera mitad y segunda mitad del siglo XIII, respectivamente. En el caso concreto de Núria, el vástago con nudo medial del pie, así como la fabricación en cobre dorado, lo acercan a cronologías propias

12. Archivo de la Corona de Aragón, Cancillería, registro 898, fol. 244 r-v. 
de los siglos XIV-XV donde será habitual este tipo de materiales frente a la paulatina desaparición del peltre.

Las piezas con exclusiva presencia de nudo de conexión entre recipiente y pie, como muestra el cáliz de Ifach parecen fecharse entre la segunda mitad del siglo XII y la primera mitad del siglo XIII, a la vista de las fechas manejadas por los autores anteriormente mencionados en sus trabajos de referencia. Por tanto, parece que nuestros ejemplares hallados en Ifach muestran una cronología formal propia de los siglos XII-XIII, aunque su contexto arqueológico -inhumación y tumba- muestra una horquilla que los situa en la segunda mitad del siglo XIV. El motivo de esta atonía cronológica puede explicarse en un uso prolongado de las piezas de Ifach, donde en un primer momento, serían fabricadas entre los años 1150-1250, siendo trasladadas posteriormente por los colonos desplazados fundamentalmente desde los Condados Catalanes hasta Ifach y utilizadas como protagonistas de la liturgia de la comunión en el templo ifacense entre 1297-1370.

\section{PROCEDENCIA DE LAS PIEZAS}

En cuanto al taller de procedencia de ambos objetos, la primera intención era explorar la posibilidad de que se tratara de un taller de procedencia valenciana. En este sentido, señalemos la existencia de corporaciones de plateros en Valencia (1298), Barcelona (antes de 1301), Cervera (1315), Tárraga (1315) y Morella (1320). Sin embargo, hemos de destacar el hecho de que el rey Jaime II disolvió buena parte de estos gremios y que no se volvieron a reorganizar hasta el año 1381 en Barcelona y en 1392 en Valencia (HEREDIA MORENO, 2011: 489-490), haciendo del todo imposible que ambas piezas se pudieran fabricar en el entorno del Reino de Valencia. Debemos, por tanto, mirar hacia otro lado.

A la vista de los paralelos existentes (Figura 18), sí que parece evidente que situemos el lugar de fabricación de ambas piezas en el área catalana, con una clara dispersión por todo el territorio, aunque la zona norte muestra un número mayor de ejemplares. Debemos destacar el caso de la importante vinculación del Condado de Urgell, el cual aloja en la actualidad algunas de las mejores piezas del repertorio y que viene mostrando una conexión cada vez más evidente con el asentamiento medieval ifacense en el Peñón, relación de la que ya hemos expuesto algunas cuestiones en trabajos recientes (MENENDEZ FUEYO, PINA MIRA, 2018a, en prensa).

Es un hecho histórico perfectamente documentado que la colonización feudal de finales del siglo XIII y la primera mitad del siglo XIV en el recién creado Reino de Valencia se realizó con población procedente de otros puntos geográficos de la Corona de Aragón, en una de las migraciones más importantes de la Península Ibérica en la Edad Media. Todos ellos, caballeros, nobles, pasando por clérigos y frailes, por los mercaderes, artesanos, los campesinos e, incluso los ladrones y aventureros huidos de la justicia conforman una parte fundamental de nuestro ADN, de nuestras raíces como pueblo. Tampoco desvelamos ningún secreto al afirmar que gran cantidad de los miles de personas y familias enteras que decidieron dejar sus lugares de origen y dirigir sus pasos hacia las nuevas tierras conquistadas para comenzar una nueva vida procedían del área catalana.

La presencia de colonos procedentes de Urgell es un hecho bien conocido por la documentación, si bien nunca se ha tratado desde el registro material hallado en villas y yacimientos medievales valencianos. Bien al contrario, como indica Enric Guinot (2012: 131), su instalación se centró allí donde se encontraban la mayoría de las medinas islámicas del momento, pero también donde se fundaron nuevas poblas cristianas de poblamiento concentrado, como por ejemplo Xábia, Gandía, Sueca o la misma Ifach. Era también el ámbito donde se concentraban las principales huertas como espacios agrícolas más atractivos a repartir entre los colonos y por esto no podemos considerar casualidad que fuese el escenario 
principal del asentamiento de los inmigrantes en tiempos de Jaime I y años posteriores, convirtiéndola así en la más poblada (GUINOT RODRÍGUEZ, 2012: 132).

Además, la antroponomia también ha permitido confirmar la extensa ocupación de colonos del Condado de Urgell en nuestro territorio, gracias a la identificación en los documentos de los antropotopónimos, esto es, un apellido que correspondía a un topónimo y que, en aquel momento, fue en muchos casos indicador de los lugares de origen de los colonos. Una práctica muy habitual iniciada entre los siglos XII y la primera mitad del XIII, momento en el que se creó la mayor parte de los apellidos medievales, coincidiendo con las migraciones al sur de la Corona de Aragón, lo que ha sido calificado por algunos investigadores como una auténtica revolución antroponímica (GUINOT RODRÍGUEZ, 2012: 129).

A esta documentación se une el interés en el conocimiento de los asentamientos realizados después de la conquista, cuya información viene, en buena parte, del actualmente discutido Llibre de Repartiment (TORRÓ ABAD, 2012: 231), así como de las actas de la burocracia real, los pergaminos de las instituciones eclesiásticas e, incluso, algún protocolo notarial. Todos ellos han confirmado de forma clara y contundente que las dos terceras partes de los migrantes llegaron desde los Condados catalanes y Mallorca, constituyen e integran lo que algunos autores han venido a denominar los fundadores del reino, en una larga dinámica de expansión territorial y de progresiva colonización de un al-Andalus en retirada (GUINOT RODRÍGUEZ, 2012: 123).

En cuanto al registro material, poco sabemos hasta la fecha. Sin embargo, a la vista de piezas como el cáliz y patena hallados en la T13 del cimiterium, parece clara la presencia de colonos procedentes del área catalana, que podemos quizás definir como una impronta, una marca de influencia que subyace en el conjunto de materiales localizado en Ifach. Si bien es variado y afecta a diferentes tipos de registro, su presencia en comparación con el res- to del conjunto arqueológico objetual recuperado hasta ahora en Ifach, hace que hablemos de él como un ruido de fondo, eso sí, constante y presente en el análisis como quizás la única manifestación exógena de producciones diferentes al registro de fabricación y origen netamente valencianos.

\section{CONCLUSIONES}

La presencia de estas piezas tan singulares en el registro material de una excavación viene dada, no solamente por la singularidad de este tipo de objetos dentro del registro arqueológico, sino por el tipo de personajes a los que se asocia la presencia de estos objetos. Como hemos señalado, la Tumba 13 es una de las escasas inhumaciones que muestra un ajuar asociado y que nos permite establecer algunos detalles interesantes que revelan la identidady funciones que desarrolló el individuo durante sus años de vida en Ifach.

Por ello, y en coincidencia con el planteamiento realizado del resto de piezas de referencia mostradas en este artículo, la presencia en el ajuar de la tumba de dos objetos litúrgicos tan representativos como el cáliz y la patena, está indudablemente asociado con la pertenencia a un clérigo o miembro de estamento clerical, que a veces incluso recogen dentro de sus testamentos cantidades destinadas a la adquisición de este tipo de objetos, como cálices o patenas litúrgicas. Además, solo los miembros pertenecientes al estamento clerical podían tocar los denominados como vasos eucarísticos (CORBLET, 1886: Tomo II, 226-227). Es por eso que hemos planteado que el individuo enterrado en la T13 de Ifach sea un clérigo, quien habitaba seguramente dentro de los muros de la pobla en la domus clerici, que aún no hemos localizado en el yacimiento y que prestó servicio en la iglesia medieval de Ifach. En el momento de su defunción, que parece que se produce en la segunda mitad del siglo XIV, fue enterrado en el cimiterium a los pies de esta iglesia, junto con los elementos litúrgicos con los cuales prestó el servicio religioso en una clara señal de su dignidad. 
Este tipo de rituales de entierro de cargos eclesiásticos no nos es desconocido, puesto que, en la práctica totalidad de los paralelos expuestos en este trabajo y documentados en el área catalana, se han localizado en contextos funerarios vinculados con importantes cargos de la rama eclesiástica, como en el caso del cáliz de Sant Ermengol, vinculado con el obispo de La Seu d'Urgell (1010-1035); el cáliz de Arnau de Creixell, Obispo de Girona entre los años 1199-1214; el cáliz de Guillem de Cabanelles, también nombrado Obispo de Girona entre los años 1227-1245; el cáliz del Obipos Benat Calbó, abad cisterciense y prelado de Vic entre los años 1233-1243 o el cáliz del Obipo Bernat d'Olivella, nombrado rector de la sede tarraconense entre 1272-1282.

En algunos casos, cáliz y patena se ven acompañados otras piezas como báculos, que identifican al obispo de un determinado territorio, caso del fragmento de báculo del Arzobispo Bernat de Olivella, encontrado en su sepulcro de la Iglesia de Santa Tecla la Vieja, junto al conjunto de la Catedral de Tarragona y datado antes de 1287 (LIAÑO MARTíNEZ, 2018: 125-150); el báculo del Obispo Arnau de Gurb (MATAS I BLANXART, 1996: 167-173), los restos del cual se conservan en el tesoro de la Catedral de Barcelona o el desaparecido báculo de Sant Pere de Àger (MATAS I BLANXART, 1999: 601-616).

Tratándose, por lo tanto, de un clérigo y al encontrarnos en Ifach, un lugar perteneciente en la Casa de Lauria, podríamos apuntar que se tratara de un clérigo franciscano (Figura 28), perteneciendo a la Orden de Frailes Menores, fundada a principios del siglo XIII por San Francisco de Asís. La elección de esta orden no es casual, puesto que la Casa de Lauria siempre ha mostrado grandes lazos de unión con esta orden y, sobre todo, con la rama femenina, la Orden de las Clarisas, de la cual Saurina de Entenza llegó a ser abadesa fundadora, como promotora de la construcción del Convento de Santa Clara la Real de Xátiva, así como numerosas obras religiosas continuadas por su hija Margarita de Lauria y Entenza, Condesa de Terranova y promotora

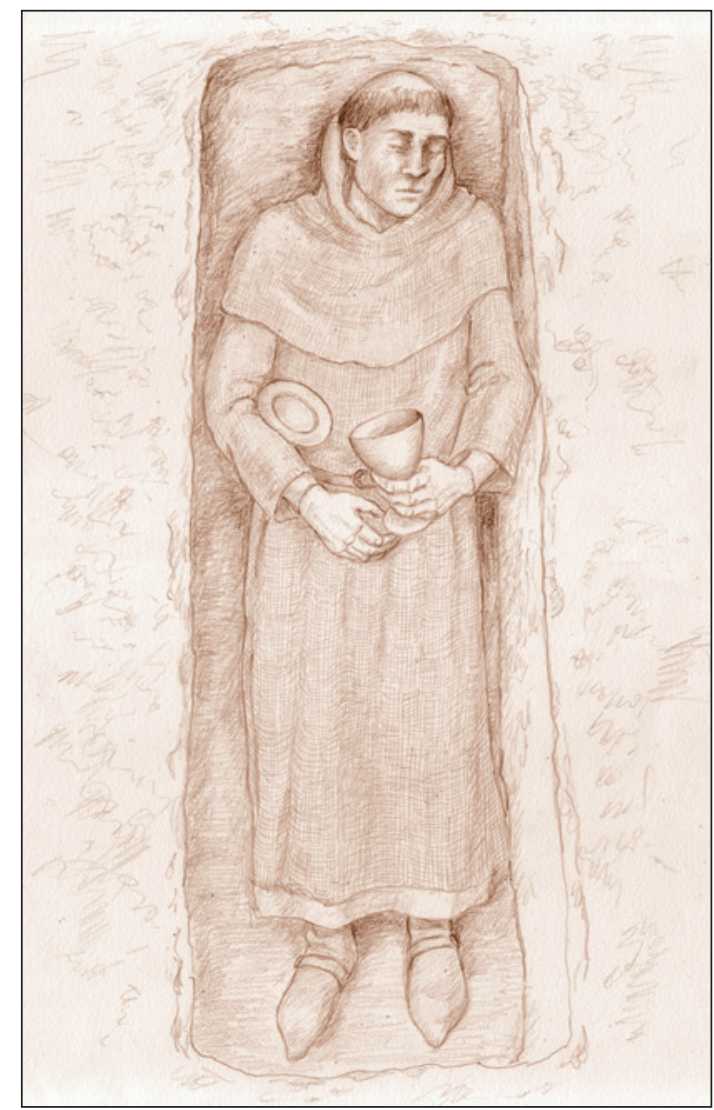

Figura 28. Reconstrucción del enterramiento de la Tumba 13. Dibujo: Pilar Mas Hurtuna. Archivo Gráfico MARQ.

de la construcción de la iglesia medieval de Ifach a mediados del siglo XIV, como hemos indicado anteriormente.

En muchos casos, -desconocemos documentalmente si en Ifach lo era- el cimiterium era proprium et francum alodium de la iglesia, y el sacerdote se encargaba de la vigilancia de la paz y de la gestión cotidiana en el área sacra, organizando las fosas y la distribución de los cuerpos de los colonos. Un aspecto interesante es que la única condición válida para el establecimiento de un cimiterium era que hubiera tenido consagración episcopal. O sea, que el obispo de la diócesis adscrito al territorio hubiera realizado la consecratio, otorgando la res sacra al edificio eclesial y a todo el perímetro formado por los triginta passuus ecclesiasticos.

No disponemos aún de documentación que apoye esta medida, ni contamos con res- 
tos arqueológicos que lo demuestren. Sin embargo, recordemos aquí aquella cita extraída de las Relaciones geográficas, topográficas e históricas del Reino de Valencia redactadas por el cosmógrafo real D. Tomás López entre los años 1760 y 1795 que se conservan en el Gabinete de Manuscritos de la Biblioteca Nacional y que fueron editadas por Tomás López de Vargas Machuca y Vicente Castañeda y Alcover entre los años 1884-1958, en las que se indica que la Iglesia de Ifach era "...un lugar arruinado del mismo nombre que el cabo y en los pedazos que quedan de la Iglesia se ven cinco escudos de armas de los obispos consacrantes..." (1998: 237). Es una posible referencia de la que aún no tenemos pruebas, pero que podría reabrirse en el futuro, ya que aún nos quedan muchas zonas en los alrededores del edificio sacro donde la arqueología todavía puede seguir aportando mucha información.

Por todo lo que se ha expuesto anteriormente, para la investigación que estamos realizando en Ifach, los resultados que ofrecen los objetos encontrados en la T13 se han convertido en una auténtica revelación, porque nos han permitido ir más allá del puro dato arqueológico y poder tejer una historia real, sin nombres, pero con caras. La T13 con su cáliz y patena suponen el hallazgo de las primeras piezas con función eclesiástica halladas en contexto arqueológico que se encuentra en nuestro territorio. Unas piezas que, a pesar de su mal estado de conservación, están ayudando a completar el perfil vital sobre los habitantes que ocuparon y construyeron la Pobla de Ifach en el siglo XIV. Una historia que hemos empezado a desentrañar, pero de la cual todavía queda mucho para conocer.

\section{REFERENCIAS}

ADELL I GISBERT, Joan-Albert, BESERAN I RAMON, Pere, SIERRA I REGUERA, Albert, VILLARÓ I BOIX, Albert, 2000: La catedral de la Seu d'Urgell, Manresa.

AINAUD I ESCUDERO, Joan-Francesc, 1989: "Calze i patena de Núria”, Millenium, Història i art de l'Església catalana, (Barcelona), p. 220.

AINAUD I ESCUDERO, Joan-Francesc, 1992: "Calze i patena de Núria”, Catalunya Medieval, (Barcelona), p. 173.
ARANEGUI GASCÓ, Carmen, 1973: "Materiales arqueológicos del Peñón de Ifac (Calpe)", Papeles del Laboratorio de Arqueología, 9 (Valencia), pp. 49-69.

ARANEGUI GASCÓ, Carmen., 1986: "Peñón de Ifach”, Arqueología en Alicante, 1976-1986, (Alicante), pp. 53-54.

ARANEGUI GASCÓ, Carmen, 1978: "Avance de la problemática de las imitaciones en cerámica de barniz negro del Peñón de Ifac", Jounées d'études de Montpellier sur la céramique campanienne (17-18 décembre 1977), Archéologie en Languedoc 1, 17-20.

ARANEGUI, Carmen ; BAZZANA, André ; 1980: «Vestiges de structures defensives d'époque romaine tardive et d'époque musulmane au Peñon d'Ifac (Calpe, province d'Alicante) », Mélanges de la Casa de Velázquez 16, (Madrid), pp. 421-436.

BARCELÓ TORRES, Carmen, 1982: Toponimia arábiga del País Valencià. Alqueries i castells, Xàtiva.

CALZADA I OLIVERAS, José, 1979: Catedral de Gerona, Barcelona.

CARBONELL I ESTELLER, Eduard, SUREDA I PONS, Joan, 1997: Tresors medievals del Museu Nacional d'Art de Catalunya, Barcelona

CARPENTER, Rhys, 1925: "El lloc d'Hemeroskopeion", Butlletí de l'Associació Catalana d'Antropologia, Etnologia i Prehistòria 2, (Valencia), pp. 187-193.

CASA MARTÍNEZ, Carlos de la, 1992: Las necrópolis medievales de Soria, Junta de Castilla y León-Diputación de Soria- AEAM, Valladolid.

CASA MARTÍNEZ, Carlos de la, 1994: "Necrópolis medieval de Tiermes III", Tiermes III, (Madrid), pp. 83-132.

CASANOVAS I ROMEU, Àngels, 1986: "Calze i patena de peltre”, Catalunya Romànica XXII, (Barcelona), p. 231.

CASANOVAS I ROMEU, Àngels, 1988: "Calze i patena de peltre 1”, Catalunya Romànica XXIII, (Barcelona), pp. 152-153.

CASANOVAS I ROMEU, Àngels, GRÀCIA MONT, Elisènda, 1986: "Calze, patena i oblata de de Sant Bernat Calbó", Catalunya Romànica XXIII, (Barcelona), pp. 229-230.

CASTELLS SERRA, Jesús, 1975: El Martirologi de l'església d'Urgell, La Seu d'Urgell.

CLARIANA I ROIG, Joan Francesc, 1991: "Noves aportacions a l'estudi de les necrópolis altomedievals del Maresme", Sessió d'Estudis Mataronins 9, (Mataró), pp. 11-25.

CLARIANA I ROIG, Joan Francesc, 1992: "Anotaciones al estudio de las necrópolis altomedievales de la comarca del Maresme", III Congreso de Arqueología Medieval Española, Tomo III, (Oviedo), pp. 493-499.

CORBLET, J., 1886: Histoire dogmatique, liturgique et archéologique du sacrement de l' Eucharistie, Typographie Edmond Monnoyer, Le Mans.

DALMAU, Guillem, 2010: "Orfevreie nord-catalane des Xe-XIIle siècles, un essai de corpus", Les Cahiers de 
Sant-Michel de Cuxa XLI, pp. 113-120.

DOMÍNGUEZ BOLANOS, A., 2003: "La documentación arqueológica de los edificios prerrománicos de San Martín de Elines", en Iglesias Gil, J.M. (ed.), Cursos sobre el Patrimonio Histórico 7. Actas de los XIII Cursos Monográficos sobre el Patrimonio Histórico (Reinosa, julio-agosto 2002), (Santander), pp. 319-330.

DURAN-PORTA, Joan, 2015: L'orfebreria románica a Catalunya (950-1250), Dos volúmenes, Tesis doctoral mecanoescrita, Universidad Autónoma de Barcelona, Barcelona.

DURLIAT, Marcel, 1954: Trésors d'orfevrerie des églises du Roussillon et du Languedoc méditerranéen, Perpiñán.

ESPAÑOL BERTRÁN, Francesca, YARZA LUACES, Joaquín, 2007: El romànic català, Manresa.

FITA I COLOMER, Fidel, 1897: "San Andrés de Llavaneras", Boletín de la real Academia de la Historia 31, (Madrid), pp. 227-240.

FOLCH I TORRES, Joaquín, 1926: Catálogo de la sección de arte románico. Museo de la Ciudadela, Barcelona.

FORT I COGULL, Eufemià, 1979: Sant Bernat Calbó, abat de Santes Creus i bisbe de Vic, Vilaseca-Salou.

GARCÍA GARCÍA, Francisco, 1986: "Els símptomes d'una recuperació econonòmica: la repoblació d'Ifac (1418)", Anales de la Universidad de Alicante. Historia medieval 4-5, (Alicante), pp. 167-174.

GIRONA, 1985: Girona dins la formació de l'Europa medieval 785-1213, catálogo de la exposición, Girona.

GRÀCIA MONT, Elisènda, 1984-1985: "Materials de peltre medievals a Catalunya", Acta histórica et archaeologica Mediaevalia 5-6, (Barcelona), pp. 313-354.

GRÀCIA MONT, Elisènda, 1986: "Altres materials de peltre medievals a Catalunya", Acta histórica et archaeologica Mediaevalia 7-8, (Barcelona), pp. 453-458.

GROS I PUJOL, Miguel de los Santos, ORDEIG I MATA, Ramón, 1980: "Exposició conmemorativa VIII Centenari del naiximent de Sant Bernat Calbó, bisbe de Vic 1180-1980", Ausa 9, (Vic), pp. 133-144.

GUDIOL I CUNILL, Josep, 1902: Nocions de arqueologia sagrada catalana, Vic.

GUDIOL I CUNILL, Josep, 1909: "Lo Sepulcre de Sant Bernat Calbó, Bisbe de Vich", III Congreso de Historia de la Corona de Aragón dedicado al rey Jaime I y su época, (Barcelona), pp. 744-750.

GUDIOL I CUNILL, Josep, 1920: El mobiliari litúrgic. Resum arqueològic, Vic.

GUDIOL I CUNILL, Josep, 1931-1933: Nocions d'arqueologia sagrada catalana, 2 vols., (Edición revisada de la obra de 1902).

GUILLAMET, Jordi; LLOVERA, Xavier, (coords.) (1989): Andorra arqueològica. Catàleg de l'exposició, Andorra la VeIla, Govern d'Andorra.
GULLATH, Brigitte, 2012: "Purpurevangeliar", Pracht auf Pergament, Catálogo de la exposición, Munich.

GUTIÉRREZ CUENCA, Enrique, 2015: Génesis y evolución del cementerio medieval en Cantabria, Tesis doctoral, Departamento de ciencias históricas, Universidad de Cantabria.

HEREDIA MORENO, María del Carmen, 2011: "La platería en la Península Ibérica en tiempos del Compromiso de Caspe", Artigrama: Revista del Departamento de Historia del Arte de la Universidad de Zaragoza 26, (Zaragoza), pp. 479-514.

IVARS PÉREZ, Josep, 1987: “El lloc d'Ifac. Una fundación del segle XIII”, Xàbiga 2, (Xàbia), pp. 35-41.

JOVER MAESTRE, Francisco Javier, LÓPEZ PADILLA, Juan Antonio, GARCÍA-DONATO LAYRÓN, Gonzalo, 2014: "Radiocarbono y estadística bayesiana: aportaciones a la cronología de la Edad del Bronce en el extremo oriental del Sudeste de la Península Ibérica", Saguntum. Papeles del Laboratorio de Arqueología de Valencia 46, (Valencia), pp. 41-69.

LIAÑO MARTÍNEZ, Emma, 2018: "Las capillas góticas de Santa Tecla la Vieja y San Pablo en Tarragona", Universitas Tarraconensis. Revista de Geografia, Història i Filosofia 3 (Tarragona), pp. 125-150.

LÓPEZ VILAR, Jordi, 1999: “L’art moble i sumptuari”, Tarragona medieval, (Tarragona), pp. 149-160.

MALAGUTTI, Stefania, FERRER CARRIÓN, Roberto, MENÉNDEZ FUEYO, Jose Luis, 2013: "Desenterrando Ifach. Primeros avances en el estudio de la necrópolis de Ifach", Butlletí Calp: Institut d'Estudis Calpins 6, (Calp), pp. 18-19.

MALAGUTTI, Stefania, MENENDEZ, Jose Luis, PINA, Joaquín, 2018: "Triginta passuss ecclesiasticos. El cimiterium medieval de Ifach", La Pobla medieval de Ifach (Calp, Alicante). 10 años de arqueología medieval en el Penyal d'lfac (2005-2015), Excavaciones Arqueológicas nº 8, (Alicante), pp. 145-178.

MARTíNEZ SUBÍAS, Antonio, 2013: Sacralia Antiqua. Diccionari del catalogador del patrimoni cultural de l'Església, Barcelona.

MATAS I BLANXART, María Teresa, 1996: "El bàcul del bisbe Arnau de Gurb: una peça litúrgica o funerària?", Lambard: Estudis d'art medieval 9, (Barcelona), pp. 167-173.

MATAS I BLANXART, Maria Teresa, 1999: "El bàcul de Sant Pere d'Àger: la pèrdua d'un unicum", Anuario de Estudios Medievales 29.1, (Barcelona), pp. 601-616.

MENÉNDEZ FUEYO, Jose Luis, 2008: "La villa medieval de Ifach y el comercio mediterráneo en los siglos XIII y XIV", Sttuture e insediamenti antichi e medievali funzionali alla viabilità commerciale terrestre e marítima, (Roma), pp. 57-74.

MENÉNDEZ FUEYO, Jose Luis, 2009: "Turres et fortalicium: la pobla medieval de Ifach, un proyecto arqueológico para el futuro", Calp, Arqueología y Museo, (Alicante), pp. 174-217.

MENÉNDEZ, J.L., FERRER, R., y PINA, J., 2012: "Las fortificaciones del poder feudal en la provincia de Alicante: El 
recinto amurallado de la pobla medieval de Ifach (Calp, Alicante) (siglos XIII-XIV)", Castelos 2010, II Simposio Internacional sobre Castillos, (Palmela): 209-225.

MENÉNDEZ FUEYO, Jose Luis, PINA MIRA, Joaquín, 2017: "Cerámicas para un nuevo reino. Las cerámicas de la repoblación feudal en la Pobla medieval de Ifach (Calp, Alicante)", MARQ. Arqueología y Museo 8, (Alicante), pp. 101-133.

MENÉNDEZ FUEYO, Jose Luis, PINA MIRA, Joaquín, 2018: "Organización y producción cerámica en los siglos XIII-XIV en el Reino de Valencia: La cerámica medieval de la Pobla de Ifach", La Pobla medieval de Ifach (Calp, Alicante). 10 años de arqueología medieval en el Penyal d'Ifac (2005-2015), Excavaciones Arqueologicas nº 8, (Alicante), pp. 179-220.

MENÉNDEZ FUEYO, Jose Luis, PINA MIRA, Joaquín, 2018a: "L’emprenta catalana i el procés de colonització a la Marina Alta a Edat Mitjana: El cas de la pobla d'Ifac (Calp, Alacant)", VI Congrés d'Estudis de la Marina Alta, (Alicante), en prensa.

MENÉNDEZ FUEYO, Jose Luis, PINA MIRA, Joaquín, FERRER CARRIÓN, Roberto, 2013: "La Pobla medieval de Ifach a la luz de los descubrimientos arqueológicos (2005-2013)", Butlletí Calp Història 6, (Calp), pp. 6-9.

MOLIST I CAPELLA, Nuria (coord.) 2012: De Sanctus Michaelis a Sant Miquel. L'església de Sant Miquel d'Olèrdola entre el segle X i el segle XXI, Ajuntament d'Olèrdola i Museu d'Arqueologia de Catalunya-Olèrdola.

MOLIST I CAPELLA, Núria, BOSCH I CASADEVALL, Josep Maria, 2012: "El cementiri medieval de Sant Miquel d'Olèrdola (Olèrdola, Alt Penedès), Arqueologia funerària al nord-est peninsular (segles VI-XII), Monografies d'Olèrdola 3.2, (Barcelona), pp. 469-494.

MOLIST, Núria, BOSCH, Josep Maria, FARRÉ, Joan.; MESTRES, Joan., 2011: "L'església i la necròpolis de Sant Miquel d'Olèrdola. Primers resultats de la intervenció arqueológica (2005-2007)", IV Congrés d'arqueologia medieval i moderna de Catalunya (Tarragona), 147-159.

MORALES HERNÁNDEZ, Fernando, 1991: "Una necrópolis medieval en el Soto del Garray”, En la España Medieval 14, (Madrid), pp. 45-75.

OLLICH I CASTANYER, Inma, 2003: "Arqueologia i vida quotidiana a l'època medieval. L'excavació i interpretació d'una casa del segle XIII al jaciment de l'Esquerda", Acta Historica et Archaeologica Mediaevalia, 23-24, (Homenatge al prof. J.R. Julià Viñamata), (Barcelona), 145-165.

ORDEIG I MATA, Ramón, 1989: Les dotálies de les esglésies de Catalunya, Universitat de Barcelona, Barcelona.

OSABA Y RUÍZ DE ERENCHÚN, Basilio; 1964: "Estudio técnico de los últimos objetos ingresados en el Museo", Boletín de la Institución Fernán González, Año 42, n 162, 1 semestre, 75-82.

PAGÉS I PARETÉS, Montserrat, 2015: Pintura catalana. El romànic, Enciclopèdia Catalana, Barcelona.

PEIRIS I PUJOLAR, Nuria, 1988: "Calze i patena de Núria", Catalunya Romànica XXIII, (Barcelona), pp. 262-263.
PEIRIS I PUJOLAR, Nuria, 1988a: "Calze de la Seu”, CataIunya Romànica XXIII, (Barcelona), pp. 261-262.

PEIRIS I PUJOLAR, Nuria, VIGUÉ I VINYES, Jordi, 1988: "Calze d'Arboló", Catalunya Romànica XXIII, (Barcelona), p. 262.

PAVÓN MALDONADO, Basilio, 1997-1998: "Calpe y al-Askar (Alicante). Sobre el hábitat medieval del Peñón de Ifach y al-Askar o Madinat al-Askar", Sharq al-Andalus. Estudios Árabes 14-15, (Alicante), pp. 81-105.

PERRIN, Joel, VASCO-ROCCA, Sandra, 1999: Thesaurus des objets religieux: meubles, objets, linges, vêtements et instruments de musique de culte catholique romain, París.

PONSICH, Pere, 1993: "Sant Salvador de Casesnoves", Catalunya Romànica XIV, (Barcelona), pp. 242-243.

PONSICH, Pere, 1993a: "Altres mostres d'art", Catalunya Romànica XIV, (Barcelona), pp. 98.

RAMON I VINYES, Salvador, 1989: "Calze i patena de l'arquebisbe Olivella”, Millenium. Història i art de l'Església Catalana, (Barcelona), p. 227.

RIU I RIU, Manuel, 1982: "Alguns costums funeraris de l'Edat Mitjana a Catalunya", Necròpolis i Sepultures Medievals a Catalunya, Acta Mediaevalia, Annex 1, (Barcelona), pp. 29-57.

ROSS, Marvin C., 2005: Catalogue of the Byzantine and Early Medieval Antiquities in the Dumbarton Oaks Collection, tomo II, Washington.

SANJOSÉ LLONGUERAS, Lourdes de, 2015: L'obra de Llemotges i d'altres origens. L'obra de metall als segles XII-XIII a Catalunya, Tesis doctoral mecanoescrita, Universidad de Barcelona, Barcelona.

SÁNCHEZ SIGNES, Miquel, 2018: "Monetam curribilis pani et vino. Estudio del conjunto numismático hallado en las excavaciones arqueológicas de la Pobla medieval de Ifach", La Pobla medieval de Ifach (Calp, Alicante). 10 años de arqueología medieval en el Penyal d'lfac (2005-2015), Excavaciones Arqueologicas nº 8, (Alicante), pp. 269-296.

SARASOLA ETXEGOIEN, Nerea, 2011: "El poblamiento medieval de Gipuzkoa. Revisión crítica del registro arqueológico", Munibe Antropologia-Arkeologia, 61, (San Sebastián), pp. 339-393.

SERRA I VILARÓ, Joan, 1960: Santa Tecla la Vieja, primitiva Catedral de Tarragona, Tarragona.

SOLÀ I MORETA, Fortià, 1952: Història de Núria, Barcelona.

VALLE DE TARAZAGA, Francisco J., BONTHORNE, Emma J., 2016: "Santa María de Zamartze: investigación de una necrópolis medieval y la mansio romana de Aracaeli", Trabajos de Arqueología Navarra 28, (Pamplona), pp. 233243.

VARIOS AUTORES, 1990: Museu Diocesà i Comarcal de Solsona. Catàleg d'Art Romànic i Gòtic, Solsona.

VIGUÉ I VINYAS, Jordi; BASTARDES I PORCEL, Albert, 1978 : El Berquedà. Monuments de la Catalunya Romànica, Barcelona. 
VIVES I MIR, Albert, 1980: "L’art d'orfebreria al Museu Diocesà d'Urgell”, Urgellia III, (La Seu d'Urgell), pp. 483-507.

WILLIAMS, John, 1994: The Illustrated Beatus, dos tomos, Harvey Miller Publishers, Londres.
ZENG, G.; MCDONALD, S.D.; SWEATMAN, K.; NOGITA, K.; 2014: "Tin pest in lead-free solders? Fundamental studies on the effect of impurities on phase transformation kinetics", International Conference on Electronics Packaging (ICEP) Proceedings, 135-139. 